\title{
Perioperative Management of Elderly patients (PriME): recommendations from an Italian intersociety consensus
}

\author{
Paola Aceto ${ }^{1,2} \cdot$ Raffaele Antonelli Incalzi ${ }^{3}$. Gabriella Bettelli $\cdot$ Michele Carron $^{5} \cdot$ Fernando Chiumiento $^{6}$. \\ Antonio Corcione ${ }^{7}$. Antonio Crucitti ${ }^{1,2} \cdot$ Stefania Maggi ${ }^{8} \cdot$ Marco Montorsi $^{9} \cdot$ Maria Caterina Pace $^{10} \cdot$ Flavia Petrini $^{11}$. \\ Concezione Tommasino ${ }^{12}$. Marco Trabucchi ${ }^{13}$. Stefano Volpato ${ }^{14}$ (I) on behalf of Società Italiana di Anestesia \\ Analgesia Rianimazione e Terapia Intensiva (SIAARTI), Società Italiana di Gerontologia e Geriatria (SIGG), Società \\ Italiana di Chirurgia (SIC), Società Italiana di Chirurgia Geriatrica (SICG) and Associazione Italiana di Psicogeriatria \\ (AIP)
}

Received: 3 March 2020 / Accepted: 3 June 2020 / Published online: 10 July 2020

(c) The Author(s) 2020, corrected publication 2020

\begin{abstract}
Background Surgical outcomes in geriatric patients may be complicated by factors such as multiple comorbidities, low functional performance, frailty, reduced homeostatic capacity, and cognitive impairment. An integrated multidisciplinary approach to management is, therefore, essential in this population, but at present, the use of such an approach is uncommon. The Perioperative Management of Elderly patients (PriME) project has been established to address this issue.

Aims To develop evidence-based recommendations for the integrated care of geriatric surgical patients.

Methods A 14-member Expert Task Force of surgeons, anesthetists, and geriatricians was established to develop evidencebased recommendations for the pre-, intra-, and postoperative care of hospitalized older patients ( $\geq 65$ years) undergoing elective surgery. A modified Delphi approach was used to achieve consensus, and the strength of recommendations and quality of evidence was rated using the U.S. Preventative Services Task Force criteria.

Results A total of 81 recommendations were proposed, covering preoperative evaluation and care (30 items), intraoperative management (19 items), and postoperative care and discharge (32 items).

Conclusions These recommendations should facilitate the multidisciplinary management of older surgical patients, integrating the expertise of the surgeon, the anesthetist, the geriatrician, and other specialists and health care professionals (where available) as needed. These roles may vary according to the phase and setting of care and the patient's conditions.
\end{abstract}

Keywords Older patients $\cdot$ Anesthesia $\cdot$ Surgery $\cdot$ Perioperative care $\cdot$ Frail older $\cdot$ Analgesia $\cdot$ Comprehensive geriatric assessment

Stefano Volpato

vlt@unife.it

1 Fondazione Policlinico Universitario A. Gemelli IRCCS, Rome, Italy

2 Università Cattolica del Sacro Cuore, Rome, Italy

3 Policlinico Universitario Campus Biomedico, Rome, Italy

4 Past Director Geriatric Surgery Area and Anaesthesia Dpt., INRCA, Italian National Research Centre on Aging, Ancona, Italy

5 Università degli Studi di Padova, Padua, Italy

6 ASL Salerno, Salerno, Italy

\footnotetext{
Monaldi-Ospedale Dei Colli, Naples, Italy

CNR, Institute of Neuroscience, Aging Branch, Padua, Italy

9 Humanitas University and Research Hospital IRCCS, Milan, Italy

10 Università degli Studi “Luigi Vanvitelli”, Naples, Italy

11 Università degli Studi G.d'Annunzio, Chieti, Italy

12 Università degli Studi di Milano, Milan, Italy

13 Università degli Studi di Tor Vergata, Rome, Italy

14 Università degli Studi di Ferrara, Ferrara, Italy
} 


\section{Introduction}

People over 65 years of age currently account for $23 \%$ of the Italian population [1], and in 2017, approximately $45 \%$ of surgical interventions were performed in this age group. The traditional clinical approach, focusing on a single disease, is often insufficient in geriatric patients, for many reasons including multiple comorbidities, low functional performance, frailty, reduced homeostatic capacity, and cognitive impairment. Geriatric surgical patients, therefore, require integrated care from the preoperative evaluation throughout the perioperative period. However, although multidisciplinary care models for geriatric patients, such as the orthogeriatric model [2], are long established, this integrated approach appears to be rarely used in older patients undergoing other major surgeries. For this reason, the PriME (Perioperative Management of the Elderly) project has been developed by a multidisciplinary panel of anesthetists, surgeons, and geriatricians, aiming to highlight the specific needs of older surgical patients, and to propose recommendations for the integrated care of geriatric surgical patients.

\section{Materials and methods}

PriME is a collaborative initiative of SIAARTI (Italian Society of Anesthesia, Analgesia, Intensive Care and Intensive Care), SIGG (Italian Society of Gerontology and Geriatrics), SIC (Italian Society of Surgery),
Society of Geriatric Surgery (SICGe), and AIP (Italian Association of Psychogeriatrics). These societies appointed a 14-member Expert Task Force, which met in September 2018 to define the scope of the project, identify key issues, and agree consensus methods. It was decided that the focus should be on hospitalized patients aged $>65$ years undergoing elective surgery; three main areas for investigation were identified (preoperative, intraoperative, and postoperative care), and corresponding subcommittees appointed. A modified Delphi approach was used to achieve consensus, and the U.S. Preventive Services Task Force system [3] used to rate the strength of recommendations (Table 1) and level of certainty/quality of evidence (Table 2).

Based on a literature review, each subcommittee developed a list of topics, and proposed specific recommendations with supporting evidence for each topic. Key issues were discussed at a meeting in January 2019, after which a comprehensive document was circulated, and subjected to three rounds of revision. Statements for which consensus was achieved (defined as $>70 \%$ agreement with $<15 \%$ disagreement) were than resubmitted to the Expert Task Force at a Consensus Conference in July 2019, where recommendations and supporting evidence were reviewed and discussed by the entire group, to achieve a final consensus. Subsequently, a draft report was prepared and sent to the Experts for modification and comment. Each author approved the final version prior to submission.

A complete list of all recommendations is included in Table 3.

Table 1 US Preventive Services Task Force grading of strength of recommendations (3)

\begin{tabular}{|c|c|c|}
\hline Grade & Definition & Suggestion for practice \\
\hline A & $\begin{array}{l}\text { The USPSTF recommends the service. There is high certainty that } \\
\text { the net benefit is substantial }\end{array}$ & Offer or provide this service \\
\hline B & $\begin{array}{l}\text { The USPSTF recommends the service. There is high certainty that } \\
\text { the net benefit is moderate or there is moderate certainty that the } \\
\text { net benefit is moderate to substantial }\end{array}$ & Offer or provide this service \\
\hline $\mathrm{C}$ & $\begin{array}{l}\text { The USPSTF recommends selectively offering or providing this } \\
\text { service to individual patients based on professional judgment and } \\
\text { patient preferences. These is at least moderate certainty that the } \\
\text { net benefit is small }\end{array}$ & $\begin{array}{l}\text { Offer or provide this service for selected patients depending on } \\
\text { individual circumstances }\end{array}$ \\
\hline $\mathrm{D}$ & $\begin{array}{l}\text { The USPSTF recommends against the service. There is moderate or } \\
\text { high certainty that the service has no net benefit or that the harms } \\
\text { outweigh the benefits }\end{array}$ & Discourage the use of this service \\
\hline I & $\begin{array}{l}\text { The USPSTF concludes that the current evidence is insufficient to } \\
\text { assess the balance of benefits and harms of the service. Evidence } \\
\text { is lacking, of poor quality, or conflicting, and the balance of } \\
\text { benefits and harms cannot be determined }\end{array}$ & $\begin{array}{l}\text { Read the clinical considerations section of USPSTF Recom- } \\
\text { mendation Statement. If the service is offered, patients should } \\
\text { understand the uncertainty about the balance of benefits and } \\
\text { harms }\end{array}$ \\
\hline
\end{tabular}


Table 2 Grading of quality of evidence ( modified from US Preventive Services Task Force (3)

\begin{tabular}{ll}
\hline Quality of evidence & Description \\
\hline High (A) & The available evidence usually includes consistent results from a multitude of well-designed, well-conducted, \\
studies in representative care populations. These studies assess the effects of the service on the desired \\
health outcomes. Because of the precision of findings, this conclusion is, therefore, unlikely to be strongly \\
affected by the results of future studies. These recommendations are often based on direct evidence from \\
clinical trials of screening, treatment or behavioral interventions. High-quality trials designed as "pragmatic" \\
or "effectiveness" trials are often of greater value in understanding external validity \\
The available evidence is sufficient to determine the effects of the service on targeted health outcomes, but \\
confidence in the estimate is constrained by factors such as: \\
The number, size, or quality of individual studies in the evidence pool \\
Some heterogeneity of outcome findings or intervention models across the body of studies \\
Mild-to-moderate limitations in the generalizability of findings to routine care practice. \\
As more information becomes available, the magnitude or direction of the observed effect could change, and \\
this change may be large enough to alter the conclusion \\
The available evidence is insufficient to assess effects on health outcomes. Evidence is insufficient because of: \\
The very limited number or size of studies \\
Inconsistency of direction or magnitude of findings across the body of evidence \\
Critical gaps in the chain of evidence \\
Findings are not generalizable to routine care practice \\
A lack of information on prespecified health outcomes \\
Lack of coherence across the linkages in the chain of evidence. \\
More information may allow an estimation of effects on health outcomes \\
Low (C)
\end{tabular}

\section{Preoperative assessment and optimization}

\section{Comprehensive geriatric assessment (CGA)}

\begin{tabular}{|c|c|c|}
\hline Statement & $\begin{array}{l}\text { Quality of } \\
\text { evidence }\end{array}$ & $\begin{array}{l}\text { Strength of rec- } \\
\text { ommendation }\end{array}$ \\
\hline $\begin{array}{l}\text { We recommend that the Timed } \\
\text { Up-and-Go (TUG) test be } \\
\text { performed for all patients. In } \\
\text { case of pathological values } \\
(>20 \text { s), Comprehensive Ger- } \\
\text { iatric Assessment (CGA) is } \\
\text { necessary }\end{array}$ & Moderate & A \\
\hline $\begin{array}{l}\text { We suggest CGA for all older } \\
\text { patients }\end{array}$ & Moderate & B \\
\hline $\begin{array}{l}\text { We recommend that this } \\
\text { preoperative assessment be } \\
\text { the responsibility of the anes- } \\
\text { thetist, in collaboration with a } \\
\text { geriatrician if available, who } \\
\text { together share assessments } \\
\text { and appropriate pathways } \\
\text { with the surgical staff }\end{array}$ & Moderate & A \\
\hline $\begin{array}{l}\text { We recommend that functional } \\
\text { reserves and independence be } \\
\text { evaluated before the interven- } \\
\text { tion }\end{array}$ & Moderate & A \\
\hline
\end{tabular}

The preoperative assessment should evaluate the patient's health status to assess the surgical risk, increase functional reserves, manage vulnerability, and anticipate, minimize, or prevent possible complications. This requires a team-based approach throughout the entire care pathway [4]. The anesthetist should guide the team in the perioperative phase, and the geriatrician should take the lead thereafter.

Comprehensive Geriatric Assessment (CGA) is a multimodal, multidisciplinary, process aimed at identifying care needs, planning care, and improving clinical and functional outcomes for older people [5]. This process includes both clinical data and functional measures of cognitive, psychological, nutritional, and behavioral status, and evaluation of social or family support. The aims are to improve diagnostic accuracy, optimize medical treatment, improve medical outcomes, optimize the home environment, minimize unnecessary service use, and arrange long-term management.

CGA and frailty evaluation are extremely useful in surgical risk evaluation in older patients, and in making decisions about surgery [4, 6-8]. However, evidence from randomized-controlled trials, large systematic reviews, and meta-analyses suggests that the effectiveness of CGA may vary according to the healthcare setting. For example, homebased and in-hospital CGA programs have consistently been shown to improve health outcomes, whereas evidence is less conclusive for post-hospital discharge CGA programs, outpatient CGA consultation, and CGA-based inpatient geriatric consultation services [9]. The effectiveness of CGA may be reduced in patients with specific clinical conditions, such as frailty, cancer, or cognitive impairment [9].

CGA is recommended in all geriatric surgical patients, and is mandatory in those with a timed up-and-go (TUG) test result $>20 \mathrm{~s}$. However, because CGA is time-consuming and sometimes difficult to apply in clinical practice, involvement 
Table 3 Summary of recommendations

\section{Preoperative assessment and optimization}

We recommend that the Timed Up-and-Go (TUG) test be performed for all patients. In case of pathological Moderate A values (>20 s), Comprehensive Geriatric Assessment (CGA) is necessary

We suggest CGA for all older patients

We recommend that this preoperative assessment be the responsibility of the anesthetist, in collaboration with a geriatrician if available, who together share assessments and appropriate pathways with the surgical staff

We recommend that functional reserves and independence be evaluated before the intervention

We suggest using multiparametric frailty scales (e.g., Fried Score or Edmonton Frailty Score) to identify areas where preoperative optimization is necessary

We recommend a systematic prehabilitation strategy to improve functional status and increase the organic functional reserve

We recommend a cardiopulmonary exercise test before major surgery (e.g., cardiovascular or thoracic) Low

Moderate A

We recommend that the risk of falls be assessed, especially in older patients with reduced mobility, postural Low hypotension, or risk of syncope, and that preventive measures be adopted

Visual and auditory aids must always be readily available and accessible to the patient, and should be removed only when their use conflicts with other needs

We recommend cognitive assessment (e.g., Clock test, AMT, and MMSE) of all patients aged $>65$ years, Moderate

We recommend a second-level specialist neurocognitive assessment for patients with pathological test scores

We recommend that the relative implications of comorbidities, and chronic or degenerative pathologies, for the response to surgery be recognized

It is recommended that the cardiovascular risk assessment includes:

- Functional capacity and, in case of major surgery, cardiac stress test (when indicated)

- A cardiac risk index (e.g., Lee Index) or a surgical risk calculator that includes age and comorbidities

(ACS-NSQIP Surgical Risk Calculator)

- Risk of cardiac complications associated with the type of surgical intervention

Before surgery, we recommend that patients at risk of venous thromboembolism be identified and appropri- Moderate ate perioperative prophylaxis be established

We recommend that risk factors for respiratory complications be assessed and reduced where possible (e.g., Moderate abstention from smoking and optimization of therapies)

We suggest the use of risk scores for postoperative pulmonary complications (ARISCAT)

We recommend that a Patient Blood Management (PBM) strategy be implemented, including hemoglobin and iron optimization, predeposit autologous blood collection, and surgical and anesthetic strategies that reduce blood loss

We recommend that hemoglobinemia be assessed in all geriatric patients, with particular attention to those aged $>80$ years

We recommend assessment of hemoglobinemia and iron metabolism in all geriatric patients who are candidates for surgery with expected blood loss $>500 \mathrm{ml}$, or who have fatigue, neoplastic disease, associated cardiovascular, respiratory or renal disease, resting tachycardia or pallor

We recommend accurate estimation of renal function by calculating eGFR using the CKD-EPI equation

We recommend evaluation of nutritional status and correction of any deficiency, especially before major surgery

We recommend that albuminemia be assessed in all older surgical patients, especially those with hepatic comorbidity, multiple comorbidities, recent major pathology or suspected malnutrition, or candidates for major surgery

In candidates for major surgery with organ failure, we recommend an estimation of hydration and volume status with an instrumental method (e.g., ultrasound estimation or bioimpedentiometry)

We recommend pre- and postoperative nutritional support (enteral or parenteral), according to the level of undernutrition and/or feeding possibilities for patients at severe nutritional risk 
Table 3 (continued)

Statement

Quality of

evidence

Low

Moderate

dent withdrawal of these medications

To reduce the incidence of postoperative delirium, we recommend:

- Identifying predisposing and precipitating risk factors early

- Adapting surgical and anesthetic techniques

- Avoiding medications that promote postoperative delirium

- Using opioid-free anesthesia or low-dose opioid anesthesia

- Monitoring for delirium (CAM, 4AT)

Every older patient should undergo a standardized pain history and physical examination

For patients with cognitive disorders, we recommend the use of specific scales (PAINAD, NOPPAIN) for the evaluation of pain

We suggest screening for depression using validated scales (e.g., the Geriatric Depression Scale), and treatment where possible

Where possible, we suggest preventive counseling (goal setting, advanced directives) in selected cases

It is recommended that the availability of family and social support be investigated during the preoperative assessment to allow planning of substitutive support measures

\section{Intraoperative management}

When positioning an older patient on the operating table, we suggest that attention be paid to conditions of the skin (e.g., atrophy, injury) and the musculoskeletal system (e.g., bone deformities, joint stiffness, and presence of prostheses)

It is recommended that positioning be adjusted according to the patient's problems, taking care to place adequate padding at bony prominences

It is recommended that the choice of anesthesia (technique/drugs/dosage) be individualized based on the characteristics of the patient and the type of intervention, in order to reduce the incidence of postoperative delirium and facilitate recovery

We recommend dose adjustment to avoid overdose, adverse hemodynamic effects, or inadequate depth of narcosis

For induction and maintenance of general anesthesia with propofol, we recommend that the dosage be reduced by $20-50 \%$ in older patients

For halogenated anesthetics, we recommend that the minimal alveolar concentration be calculated according to patient age

Because the effect of anesthetics on the central nervous system is age-dependent, we recommend that halogenated and intravenous anesthetic dosages be modulated using an anesthesia depth monitoring system

During general anesthesia, we recommend EEG-based monitoring to avoid excessive anesthesia depth, which is associated with increased risk of postoperative delirium

It is recommended that EEG-based monitoring is extended to procedures performed under sedation

In patients undergoing general anesthesia with neuromuscular block, we recommend that neuromuscular function be monitored quantitatively, and its complete recovery (train-of-four ratio $>0.9$ ) be facilitated at the end of the intervention

We recommend that residual neuromuscular block always be antagonized

We recommend the use of sugammadex when complete and fast recovery of rocuronium-induced neuromuscular block is required

We recommend the use of sugammadex when anticholinesterases are ineffective for reversing rocuroniuminduced neuromuscular block

We recommend body-temperature monitoring and active warming of the patient, preferably with a forcedair system, during the pre-, intra- and postoperative periods

If forced-air heating is only partially efficacious (e.g., during prolonged open abdominal surgery), we suggest that warm intravenous fluids be administered

We recommend adequate monitoring to maintain a "near-zero" fluid balance

We recommend that transfusion in geriatric patients follows a restrictive transfusion strategy (red blood cell transfusion threshold: $\mathrm{Hb}<8 \mathrm{~g} / \mathrm{dl}$ )

We recommend red blood cell transfusion when symptoms of intraoperative hypoxia and/or lactic acidosis and hemorrhage are present, regardless of the severity of anemia

We suggest using minimally invasive techniques in older patients, to reduce the endocrine/metabolic response to stress and improve postoperative outcomes
Strength of recommendation
Low

Low

Low

Low

Low

Low

Moderate

Moderate

Moderate

Moderate

Moderate

High

High

Moderate

Moderate

Moderate

Moderate

High

High

High

High

High

Moderate
A

A

A

A

B

B

A

B

A

A

A

A

A

A

A

A

A

A

A

B

A

A

A

B 
Table 3 (continued)

During laparoscopy, we recommend:

- Avoiding exaggerated or prolonged Trendelenburg or anti-Trendelenburg positions

- Avoiding unjustified prolongation of surgical times

- Using the lowest possible intraperitoneal pressure $(<12 \mathrm{mmHg})$, to minimize the negative cardiovascular and respiratory effects caused by pneumoperitoneum

- Administering deep neuromuscular blockade, to allow the use of low working pressures

Postoperative care

In the postoperative period, we recommend:

- Optimal postoperative pain control

- Early mobilization and walking

- Early resumption of feeding

- Conservation of the sleep-wake rhythm

- Reducing use of nasogastric tube and bladder catheters

- Antithrombotic prophylaxis

We recommend the use of Enhanced Recovery Pathways for older patients, according to the type of surgery performed

It is recommended that prevention, recognition, and treatment of postoperative delirium must be an objective of the multidisciplinary team

We recommend that patients at risk for POD be monitored with validated diagnostic tools such as the CAM or 4AT, starting when they wake from anesthesia and continuing for 5 days thereafter

Because of the high risk (e.g., of aspiration pneumonia), we recommend the use of adequate prophylaxis against postoperative nausea and vomiting, and semi-Fowler's decubitus position

Personalized prevention and treatment of postoperative pain are mandatory. We recommend a multimodal approach or, when possible, locoregional or plane blocks (e.g., TAP block)

We suggest encouraging use of the non-pharmacological components of the multimodal approach

We recommend periodic evaluation of oxygen saturation and respiratory rate in the postoperative period

We recommend that arterial blood gas analysis be used when conditions interfere with percutaneous oximetry (e.g., shivering, tremor, cold skin, hyperthermia, hypotension, advanced heart failure, high fever, atrial fibrillation, or other arrhythmias)

We suggest that older patients should be treated with lung expansion techniques, such as deep breathing exercises, incentive spirometry, or, when indicated, with non-invasive ventilation

To prevent postoperative cardiac complications, we recommend monitoring (continuously in selected cases) and maintenance of cardiovascular measures (e.g., heart rate, arterial pressure) within baseline values

We suggest the use of graduated compression stockings or intermittent pneumatic compression, when indicated

For prevention of renal damage, we recommend that adequate hydration be maintained, and hypovolemia and/or hypotension be avoided

We recommend caution in the use of potentially nephrotoxic drugs or drug combinations with a high risk of nephrotoxicity, and in the administration of contrast media for radiological procedures

We recommend that urinary catheters be used only when essential, and be removed as soon as possible

We recommend to adopt strategies to prevent urinary tract infections before, during and after insertion of a urinary catheter

We do not recommend complementary strategies (such as the use of alpha-blockers in men) to promote spontaneous urinary function after catheter removal

It is recommended that older patients undergo daily assessment of caloric intake and water balance

We recommended that swallowing should be evaluated, and the presence of oral lesions excluded in patients with signs and symptoms of dysphagia or a history of aspiration pneumonia

We suggest that all older patients are seated during meals and for an hour after eating

It is recommended that nutritional supplementation be given in patients with malnutrition or inadequate nutrition

It is recommended that dental prostheses, if used, are readily available and easily accessible

Strategies to prevent and treat pressure injuries are recommended in patients at risk

We recommend guideline-consistent antimicrobial prophylaxis in older patients, considering antibiotic pharmacodynamics and pharmacokinetics to avoid overdoses and drug-related adverse events
Quality of

evidence

Moderate

Strength of recommendation

A

Moderate

A

Moderate

A

Moderate

A

Moderate

A

Low

A

Low

A

Low

Moderate

Moderate

B

A

A

Moderate

High

A

High

High

A

A

High A

High A

High D

Moderate A

Moderate A

Moderate B

Moderate A

Moderate A

Moderate A

Moderate A 
Table 3 (continued)

\begin{tabular}{|c|c|c|}
\hline Statement & $\begin{array}{l}\text { Quality of } \\
\text { evidence }\end{array}$ & $\begin{array}{l}\text { Strength of recom- } \\
\text { mendation }\end{array}$ \\
\hline $\begin{array}{l}\text { We recommend careful and prolonged assessment of blood glucose in older patients with or without diabe- } \\
\text { tes. } \\
\text { Insulin is the treatment of choice for the management of hyperglycemias }\end{array}$ & Moderate & A \\
\hline We suggest that blood glucose values up to $180 \mathrm{mg} / \mathrm{dl}$ are acceptable in critical postoperative patients & Moderate & B \\
\hline $\begin{array}{l}\text { During the surgical planning, we recommend evaluating the probability of the patient returning home at the } \\
\text { end of the hospital stay }\end{array}$ & Moderate & A \\
\hline $\begin{array}{l}\text { For patients with functional deterioration and/or weak social networks, we recommend that the discharge } \\
\text { plan, including outpatient visits and medications, should be organized in advance in collaboration with } \\
\text { the geriatrician; ideally, a Geriatric Evaluation Unit should be available }\end{array}$ & Moderate & A \\
\hline $\begin{array}{l}\text { Before hospital discharge, we recommend re-evaluating and adjusting drug therapy according to home } \\
\text { therapy, the surgery performed, comorbidities, and any new pathological changes }\end{array}$ & Moderate & A \\
\hline $\begin{array}{l}\text { We recommend that the patient and caregiver be provided with resources to deal with problems that may } \\
\text { arise at home, and with patient management contacts and references (telephone/e-mail) }\end{array}$ & Moderate & A \\
\hline
\end{tabular}

of hospital medical services to create specific management pathways is needed to implement this approach.

Frailty

\begin{tabular}{lll}
\hline Statement & $\begin{array}{l}\text { Quality of } \\
\text { evidence }\end{array}$ & $\begin{array}{l}\text { Strength of } \\
\text { recommendation }\end{array}$ \\
\hline $\begin{array}{l}\text { We suggest using } \\
\text { multiparametric } \\
\text { frailty scales (e.g., }\end{array}$ & Low & B \\
Fried Score or & \\
$\begin{array}{l}\text { Edmonton Frailty } \\
\text { Score) to identify } \\
\text { areas where preop- } \\
\text { erative optimization } \\
\text { is necessary }\end{array}$ & \\
\hline
\end{tabular}

Frailty is an age-related decline in physiological reserves that results in diminished resilience, loss of adaptive capacity, and increased vulnerability to stressors. Signs of frailty include unintentional weight loss, self-reported exhaustion, slow walking speed, weak grip strength, and low physical activity level [10]. Frailty is strongly predictive of adverse postoperative outcomes, including medical complications, prolonged hospitalization, institutionalization, readmission, and short- and long-term mortality [11, 12]. Hence, the American College of Surgeons National Surgical Quality Improvement Program/American Geriatrics Society (ACSNSQIP/AGS) 2012 Guidelines for the optimal pre-operative assessment of geriatric surgical patients have identified frailty assessment as a critical component in the pre-operative assessment [13], and this was reinforced by a 2015 consensus statement [14].
The Edmonton Frail Scale (EFS) [15] is a 17-point scale incorporating 10 clinical and functional domains. It is not time-consuming, and can be easily used by non-geriatricians.

Prehabilitation strategy

\begin{tabular}{lll}
\hline Statement & $\begin{array}{l}\text { Quality of } \\
\text { evidence }\end{array}$ & $\begin{array}{l}\text { Strength of } \\
\text { recommendation }\end{array}$ \\
\hline $\begin{array}{l}\text { We recommend a systematic pre- } \\
\text { habilitation strategy to improve } \\
\text { functional status and increase } \\
\text { the organic functional reserve }\end{array}$ & A \\
$\begin{array}{l}\text { We recommend a cardiopulmo- } \\
\text { nary exercise test before major }\end{array}$ & Low & A \\
surgery (e.g., cardiovascular or \\
thoracic)
\end{tabular}

Patients with functional impairment are at increased risk of postoperative complications [16]. Appropriate measures, where needed, should, therefore, be taken to increase functional reserves. 
Prehabilitation Patients with functional deficits in activities of daily living, or difficulties with mobility, should be referred to an occupational or physical therapist. Such patients may benefit from preoperative physical conditioning (prehabilitation) to enhance their capacity to withstand surgical stress and promote postoperative recovery [17]. Multimodal prehabilitation, including home exercise, nutrition assessment, and pain management, improves postoperative functional outcomes in older surgical patients [18].

Cardiopulmonary exercise testing Cardiopulmonary exercise testing objectively measures aerobic fitness or functional capacity. It provides an individualized estimate of patient risk that can be used to predict postoperative morbidity and mortality, inform decision-making, determine the most appropriate perioperative care environment, diagnose unexpected comorbidities, optimize medical comorbidities preoperatively, and direct individualized preoperative exercise programs [19].

Falls Falls are the primary cause of unintentional injury, and a leading cause of death, in older adults. Limited mobility and falls lead to functional decline, hospitalization, institutionalization, and increased health care costs [20]. A history of falls within 6 months before surgery is associated with increased rates of postoperative complications, discharge to a rehabilitation facility, and hospital readmission [21]. Hence, it is recommended that the risk of falls be assessed preoperatively, and appropriate preventive measures taken, particularly in patients with reduced mobility, postural hypotension, or risk of syncope. The risk of falls can be assessed with the TUG test [22].

Sensory deficits and use of functional aids Concomitant sensory and cognitive impairment is common in older individuals [23], and is an independent risk factor for postoperative death and complications [24]. Multimodal interventions including elements addressing visual or hearing impairment can significantly reduce the prevalence and duration of delirium in older hospitalized patients [25]. Hence, the NSQIP/AGS guidelines state that strategies for the prevention of postoperative delirium may include functional aids for visual and hearing impairment, and that such aids should be made available to the patient after surgery [13]. The patient's level of comprehension should be systematically checked at critical steps of the care process.

\section{Cognitive function}

\begin{tabular}{lll}
\hline Statement & $\begin{array}{l}\text { Quality of } \\
\text { evidence }\end{array}$ & $\begin{array}{l}\text { Strength of } \\
\text { recommendation }\end{array}$ \\
\hline $\begin{array}{l}\text { We recommend cog- } \\
\text { nitive assessment }\end{array}$ & Moderate & A \\
(e.g., Clock test, & & \\
AMT, and MMSE) & & \\
of all patients & \\
aged $\geq 65$ years, & \\
even in the absence & \\
of a history of cog- & \\
nitive decline & \\
We recommend & \\
a second-level & \\
specialist neurocog- & \\
nitive assessment & \\
for patients with & \\
pathological test & \\
scores & \\
\hline
\end{tabular}

In Europe, 35-50\% of persons older than 65 years have mild cognitive impairment (MCI) or dementia [26, 27]. However, cognitive impairment—particularly MCI-is often undiagnosed [28-30]. Postoperative delirium (POD) and postoperative cognitive dysfunction (POCD) affect $20-80 \%$ and $12-15 \%$, respectively, of geriatric surgical patients; preexisting cognitive impairment is a risk factor for both conditions, as well as being a predictor or modifier of postoperative outcomes [31-33]. Routine screening for cognitive impairment should, therefore, be included in the preoperative evaluation, even in patients with no history of cognitive decline. Basic cognitive tests, such as the Clock drawing test, the Abbreviated Mental Test, or the Mini-Mental State Examination (MMSE), can be used for screening; specialist investigation is required in patients with equivocal findings.

\section{Comorbidities}

\begin{tabular}{lll}
\hline Statement & $\begin{array}{l}\text { Quality of } \\
\text { evidence }\end{array}$ & $\begin{array}{l}\text { Strength of recommen- } \\
\text { dation }\end{array}$ \\
\hline $\begin{array}{l}\text { We recommend that the } \\
\text { relative implications } \\
\text { of comorbidities, and }\end{array}$ & A \\
chronic or degenerative & \\
pathologies, for the & \\
response to surgery be & \\
recognized & \\
\hline
\end{tabular}


The combination of aging and comorbidities is the principal factor reducing tolerance to surgical stress in older patients [4]. Comorbidities increase markedly with age, largely due to increasing rates of chronic conditions [10]. The most common comorbidity in older patients is hypertension, which affects $45-50 \%$ of patients over 70 years of age, followed by coronary artery disease (CAD) (35\%); other common comorbidities include diabetes (12-15\%) and chronic obstructive pulmonary disease (COPD) (9\%) [34]. Comorbidities are strongly associated with increased surgical and postoperative risks, and increased health care costs [35].

\section{Cardiovascular}

\begin{tabular}{lll}
\hline Statement & $\begin{array}{l}\text { Quality of } \\
\text { evidence }\end{array}$ & $\begin{array}{l}\text { Strength of recom- } \\
\text { mendation }\end{array}$ \\
\hline $\begin{array}{l}\text { It is recommended that the car- } \\
\text { diovascular risk assessment }\end{array}$ & Moderate & A \\
includes: & \\
- Functional capacity and, in \\
case of major surgery, cardiac \\
stress test (when indicated) \\
- A cardiac risk index (e.g., Lee \\
Index) or a surgical risk cal- \\
culator that includes age and \\
comorbidities (ACS-NSQIP \\
Surgical Risk Calculator) \\
- Risk of cardiac complications \\
associated with the type of \\
surgical intervention \\
Before surgery, we recom- \\
mend that patients at risk of \\
venous thromboembolism \\
be identified and appropri- \\
ate perioperative prophylaxis \\
established
\end{tabular}

Age-related changes in the cardiovascular and autonomic nervous systems reduce cardiac responsiveness to stress [36]. Guidelines for the evaluation of cardiac risk published by the American College of Cardiology (ACC) and the American Heart Association (AHA) [37] recommend preoperative cardiac testing only if the results will change clinical management, and avoidance of testing before lowrisk surgery. The type of surgery is an important determinant of the risk of cardiac complications and mortality. In patients undergoing noncardiac surgery, functional status, generally defined in terms of metabolic equivalents (METs), is a reliable predictor of both perioperative and long-term risk [38].

The Lee index [39] is widely used for assessment of cardiac risk, because it is simple and has been extensively validated. However, more recent measures, such as that of Alrezk et al. [40], may be more accurate in older patients. The ACS-NSQIP Surgical Risk Calculator [41] has been specifically validated in geriatric patients, and is an accurate tool for preoperative assessment in this population, especially if combined with cardiac biomarkers [42].

The risk of postoperative venous thromboembolism is increased in patients over 70 years of age, and in geriatric patients with comorbidities such as cardiovascular disorders, malignancy or renal insufficiency. Therefore, risk stratification, correction of modifiable risks, and sustained perioperative thromboprophylaxis are essential in these populations. The timing and dosing of thromboprophylaxis in older patients should be the same as in younger patients [43].

\section{Respiratory}

\begin{tabular}{|c|c|c|}
\hline Statement & $\begin{array}{l}\text { Quality of } \\
\text { evidence }\end{array}$ & $\begin{array}{l}\text { Strength of rec- } \\
\text { ommendation }\end{array}$ \\
\hline $\begin{array}{l}\text { We recommend that risk factors } \\
\text { for respiratory complications } \\
\text { be assessed and reduced } \\
\text { where possible (e.g., absten- } \\
\text { tion from smoking, optimiza- } \\
\text { tion of therapies) }\end{array}$ & Moderate & A \\
\hline $\begin{array}{l}\text { We suggest the use of risk } \\
\text { scores for postoperative } \\
\text { pulmonary complications } \\
\text { (ARISCAT) }\end{array}$ & Moderate & B \\
\hline
\end{tabular}

Postoperative pulmonary complications (PPCs) are common in geriatric patients, and contribute to the risks of perioperative and postoperative morbidity and mortality. The surgical site is the most important predictor of pulmonary complications; others include COPD, recent smoking, poor general health status, and functional dependency [44]. Age is a minor risk factor after adjustment for comorbidities, conferring an approximately twofold increase in risk [45]. Thus, older patients who are otherwise acceptable surgical candidates should not be denied surgery solely on the basis of concern about potential PPCs [46].

Routine preoperative spirometry is not recommended before high-risk surgery, because it is no more accurate in predicting risk than clinical evaluation. Patients who might benefit from preoperative spirometry include those with unexplained dyspnea or exercise intolerance, and those with COPD or asthma in whom the extent of airflow obstruction is unknown. A seven-variable risk assessment tool has been developed by the ARISCAT (Assess Respiratory Risk in Surgical Patients in Catalonia) Group [47], and prospectively validated [48].

Strategies for reducing the risk of PPCs in older surgical patients include risk factor minimization or avoidance (including preoperative smoking cessation), optimization of COPD or asthma treatment, deep breathing exercises, and epidural local anesthesia [46, 49]. In a general population of patients scheduled for elective upper abdominal surgery, a 
30-min preoperative physiotherapy session provided as part of an existing multidisciplinary preadmission evaluation was shown to halve the incidence of PPCs, particularly hospitalacquired pneumonia [50].

\section{Hematological}

\begin{tabular}{lll}
\hline Statement & $\begin{array}{l}\text { Quality of } \\
\text { evidence }\end{array}$ & $\begin{array}{l}\text { Strength of rec- } \\
\text { ommendation }\end{array}$ \\
\hline $\begin{array}{l}\text { We recommend that a Patient } \\
\text { Blood Management (PBM) } \\
\text { strategy be implemented, }\end{array}$ & Moderate & A \\
including hemoglobin and & \\
iron optimization, predeposit & \\
autologous blood collection, & \\
and surgical and anesthetic & \\
strategies that reduce blood & \\
loss & \\
We recommend that hemo- & Moderate & A \\
globinemia be assessed in & \\
all geriatric patients, with & \\
particular attention to those & \\
aged $>80$ years & \\
We recommend assessment & Moderate & A \\
of hemoglobinemia and iron & \\
metabolism in all geriatric & \\
patients who are candidates for & \\
surgery with expected blood & \\
loss $>500$ ml, or who have & \\
fatigue, neoplastic disease, & \\
associated cardiovascular, & \\
respiratory or renal disease, & \\
resting tachycardia, or pallor & \\
\hline
\end{tabular}

Anemia is common in surgical patients, and is associated with increased perioperative mortality [51]. Preoperative anemia should, therefore, be considered a significant medical condition, rather than as simply an abnormal laboratory finding [52]. Preoperative anemia and iron deficiency are indications for a care pathway extending from the decision to operate until complete recovery, and anemia should be investigated before all surgical procedures with moderate-to-high anticipated blood loss (>500 ml) [53]. Investigation should begin with an assessment of iron status: when ferritin or iron saturation levels indicate an absolute iron deficiency, referral to a gastroenterologist may be indicated to exclude gastrointestinal malignancy as a source of chronic blood loss. In the absence of an absolute iron deficiency, measurement of serum creatinine and glomerular filtration rate (GFR) may indicate chronic kidney disease (CKD) and the need for referral to a nephrologist. When ferritin or iron saturation values are inconclusive, further evaluation is necessary to exclude inflammation or chronic disease. A therapeutic trial of iron would confirm absolute iron deficiency, whereas a lack of response would indicate anemia of chronic disease, suggesting that treatment with an erythropoietin-stimulating agent should be initiated [54]. Iron-deficiency anemia should be treated with iron supplementation [55]. Oral iron replacement should be targeted to patients with iron deficiency with or without anemia whose surgery is scheduled $6-8$ weeks after diagnosis [53].

Anemia and transfusion are associated with increased morbidity and mortality in surgical patients [56]. PBM (Patient Blood Management) is a multimodal, multidisciplinary, strategy aimed at minimizing the use of blood products and improving patients' outcomes [57]. This strategy involves optimizing hemoglobin levels, minimizing perioperative blood loss, and optimizing the patient's physiological reserve to withstand anemia [58]. PBM should be started before surgery, and continued throughout the perioperative period. Systematic preoperative PBM has consistently been shown to improve postoperative clinical outcomes [56, 59]. Maintenance of a preoperative hemoglobin level above $12.0 \mathrm{~g} / \mathrm{dl}$ is recommended in older orthopedic patients, to reduce the need for perioperative blood transfusion [60]. Intraoperative PBM includes monitoring anemia and related physiological changes, conserving autologous blood, and using surgical and anesthetic strategies to contain and minimize blood loss. During the postoperative period, monitoring of anemia, organ perfusion, blood loss, and hemostasis is an important part of clinical management [58].

\section{Renal}

\begin{tabular}{lll}
\hline Statement & $\begin{array}{l}\text { Quality of } \\
\text { evidence }\end{array}$ & $\begin{array}{l}\text { Strength of recom- } \\
\text { mendation }\end{array}$ \\
\hline $\begin{array}{l}\text { We recommend accurate } \\
\text { estimation of renal func- } \\
\text { tion by calculating eGFR }\end{array}$ & Moderate & A \\
$\begin{array}{l}\text { using the CKD-EPI } \\
\text { equation }\end{array}$ & \\
\hline
\end{tabular}

The age-related decline of renal function varies markedly, due to nephrotoxic effects of comorbidities such as hypertension or diabetes, and drug treatment, particularly with nonsteroidal anti-inflammatory drugs (NSAIDs) and angiotensin -converting enzyme (ACE) inhibitors. Renal impairment can affect anesthetic pharmacokinetics and pharmacodynamics, and hence, renal function should be assessed before any surgery in older patients [36]. The widely used Chronic Kidney Disease-Epidemiology Collaboration (CKD-EPI) equation for measuring estimated glomerular filtration rate (eGFR) is appropriate for use in this population. 


\section{Nutritional}

\begin{tabular}{|c|c|c|}
\hline Statement & $\begin{array}{l}\text { Quality of } \\
\text { evidence }\end{array}$ & $\begin{array}{l}\text { Strength of } \\
\text { recommendation }\end{array}$ \\
\hline $\begin{array}{l}\text { We recommend evaluation of } \\
\text { nutritional status and correc- } \\
\text { tion of any deficiency, espe- } \\
\text { cially before major surgery }\end{array}$ & Moderate & A \\
\hline $\begin{array}{l}\text { We recommend that albumine- } \\
\text { mia be assessed in all older } \\
\text { surgical patients, especially } \\
\text { those with hepatic comorbid- } \\
\text { ity, multiple comorbidities, } \\
\text { recent major pathology or } \\
\text { suspected malnutrition, or } \\
\text { candidates for major surgery }\end{array}$ & Moderate & A \\
\hline $\begin{array}{l}\text { In candidates for major sur- } \\
\text { gery with organ failure, we } \\
\text { recommend an estimation of } \\
\text { hydration and volume status } \\
\text { with an instrumental method } \\
\text { (e.g., ultrasound estimation or } \\
\text { bioimpedentiometry) }\end{array}$ & Moderate & A \\
\hline $\begin{array}{l}\text { We recommend preoperative } \\
\text { and postoperative nutritional } \\
\text { support (enteral or parenteral), } \\
\text { according to the level of } \\
\text { undernutrition and/or feeding } \\
\text { possibilities for patients at } \\
\text { severe nutritional risk }\end{array}$ & Moderate & A \\
\hline
\end{tabular}

Increasing age is often associated with an unhealthy nutritional status [61], which is a risk factor for postoperative complications [36, 62]. However, poor nutritional status is often insidious and, hence, often goes unrecognized. Assessment of nutritional status is, therefore, essential in older surgical patients $[63,64]$. European Society for Clinical Nutrition and Metabolism (ESPEN) guidelines emphasize the importance of screening for malnutrition on admission or first contact, observation and documentation of food intake, regular assessment of weight and body mass index (BMI), and nutritional counseling [65].

Preoperative albumin levels predict postoperative outcomes [65-67]. A preoperative serum albumin concentration of $3 \mathrm{~g} / \mathrm{dl}$ may be considered to indicate severe nutritional risk, as may a weight loss of $>10-15 \%$ within 6 months, or a BMI $<20 \mathrm{~kg} / \mathrm{m}^{2}$. Patients at high nutritional risk before elective surgery should be managed with a multimodal approach including evidence-based interventions to optimize nutritional status, and surgery should be postponed if possible [68].

\section{Medication}

\begin{tabular}{lll}
\hline Statement & $\begin{array}{l}\text { Quality of } \\
\text { evidence }\end{array}$ & $\begin{array}{l}\text { Strength of } \\
\text { recommendation }\end{array}$ \\
\hline $\begin{array}{l}\text { It is recommended that the pharma- } \\
\text { cological history must be extended } \\
\text { to include all drugs used by the }\end{array}$ & Low & A \\
patient, including over-the-counter & & \\
and herbal medicines & Low & A \\
$\begin{array}{l}\text { If the patient is taking inappropri- } \\
\text { ate medications (e.g., according } \\
\text { to STOPP criteria), we recom- } \\
\text { mend prudent withdrawal of these } \\
\text { medications }\end{array}$ & \\
\end{tabular}

In one study, $55.3 \%$ of surgical patients aged $\geq 65$ years received a potentially inappropriate medication in hospital [69], highlighting the need to recognize such inappropriate medications in the perioperative period. A comprehensive medication review, including over-the-counter medications, vitamins, and herbal supplements, is essential to identify medications that should be continued during the perioperative period, and potentially harmful, ineffective, or contraindicated medications [16]. This may be particularly important in patients experiencing, or at increased risk of, delirium, because any medication change could trigger delirium [70]. Treatment with anticholinergics and poly-medication are considered predisposing risk factors for POD; because anticholinergic compounds are present in a number of medications frequently prescribed to older patients for different purposes, the total anticholinergic burden should be considered in patients at risk of POD [71].

ACS/AGS Best Practices Guidelines [72] recommend that the immediate preoperative period is an ideal time to confirm that a plan for the perioperative management of nonessential chronic medications is in place. A number of validated tools are available to identify potentially inappropriate medications among older patients, including the updated Beers criteria [73] and the Screening Tool of Older Persons' Prescriptions (STOPP) and Screening Tool to Alert to Right Treatment (START) criteria [74]. 


\section{Delirium}

\begin{tabular}{lll}
\hline Statement & $\begin{array}{l}\text { Quality of } \\
\text { evidence }\end{array}$ & $\begin{array}{l}\text { Strength of } \\
\text { recommendation }\end{array}$ \\
\hline $\begin{array}{l}\text { To reduce the incidence } \\
\text { of postoperative }\end{array}$ & Moderate & A \\
delirium, we recom- & \\
mend: & \\
- Identifying predispos- & \\
ing and precipitating \\
risk factors early \\
- Adapting surgical and \\
anesthetic techniques \\
- Avoiding medications \\
that promote postop- \\
erative delirium \\
Using opioid-free \\
anesthesia or low-dose \\
opioid anesthesia \\
- Monitoring for \\
delirium (CAM, 4AT)
\end{tabular}

Delirium is an acute fluctuating alteration of mental state, reduced awareness, and disturbance of attention, that may be triggered by acute medical illness, surgery, trauma, or drugs [75, 76]; multiple factors may be present in an individual patient $[77,78]$. Delirium is independently linked with poor postoperative outcomes, including medical complications, falls, prolonged hospitalization, permanent cognitive dysfunction, need for institutionalization, and death, and can cause significant patient and care giver distress. It is frequently missed in routine clinical care [79, 80]. European Society of Anaesthesiology (ESA) guidelines recommend that the preoperative evaluation should include identification of potential risk factors for postoperative delirium, to identify patients at high risk [70, 81]. If a specialist geriatrician is not available, preoperative screening for delirium risk should be performed by anesthetists, and the best strategic approach determined by the multidisciplinary team [82].

The Confusion Assessment Method (CAM) may be useful in screening for delirium [79], but sensitivity and specificity vary markedly, possibly due to the need for users to have training and knowledge of delirium. The Arousal, Attention, Abbreviated Mental Test 4, and Acute change Test (4AT) is brief and easy to use without specific training, and has wide applicability in various clinical settings [83]. It offers good sensitivity and patient completion rates [84], and can also be used to assess older patients presenting in emergency departments [83].

In patients over 60 years of age, avoiding episodes of deep anesthesia during surgery lasting more than $1 \mathrm{~h}$ can significantly reduce the risk of postoperative delirium. To avoid excessively deep anesthesia, guidelines from the UK recommend that depth of anesthesia should be monitored in all patients in this age group [77, 78].
Several classes of medication can increase the risk of delirium, and hence, medication review can decrease rates of delirium [77, 78]. Opioids can cause delirium, but remain vital for treating pain, which, in itself, can precipitate delirium. The perioperative analgesia plan must consider multimodal strategies and reducing the use of opioids: older patients have increased sensitivity to opioids, and need individual dose titration [85].

\section{Pain}

\begin{tabular}{lll}
\hline Statement & $\begin{array}{l}\text { Quality of } \\
\text { evidence }\end{array}$ & $\begin{array}{l}\text { Strength of } \\
\text { recommendation }\end{array}$ \\
\hline $\begin{array}{l}\text { Every older patient should } \\
\text { undergo a standardized } \\
\text { pain history and physical } \\
\text { examination }\end{array}$ & Low & \\
For patients with cognitive & & \\
disorders, we recommend \\
the use of specific scales \\
(PAINAD, NOPPAIN) for \\
the evaluation of pain
\end{tabular}

Older patients should undergo a standardized pain history and physical examination, to determine an appropriate analgesic plan [72]. Because cognitive impairment alters the experience of pain, the ability to communicate that experience, and the medical management of pain [86], specific behavioral scales have been developed to assess pain in cognitively impaired older adults [87]. These include the Non-communicative Patient's Pain Assessment Instrument (NOPPAIN) [88], and the Pain Assessment in Advanced Dementia (PAINAD) [89].

\section{Emotional status}

\begin{tabular}{lll}
\hline Statement & $\begin{array}{l}\text { Quality of } \\
\text { evidence }\end{array}$ & $\begin{array}{l}\text { Strength of } \\
\text { recommendation }\end{array}$ \\
\hline $\begin{array}{l}\text { We suggest screening for depres- } \\
\text { sion using validated scales (e.g., } \\
\text { the Geriatric Depression Scale), }\end{array}$ & Low & B \\
$\begin{array}{l}\text { and treatment where possible } \\
\begin{array}{l}\text { Where possible, we suggest preven- } \\
\text { tive counseling (goal setting, } \\
\text { advanced directives) in selected } \\
\text { cases }\end{array}\end{array}$ & B \\
\hline
\end{tabular}

Approximately $15 \%-20 \%$ of adults aged $\geq 65$ years are affected by depression, and the prevalence among preoperative geriatric patients is even higher [61]. Depressive symptoms are associated with poor functional recovery and increased likelihood of institutionalization after discharge 
[90]. Similarly, patients with preoperative anxiety and depressive symptoms have worse patient-reported outcomes than those without [91]. Patients with preoperative depressive symptoms are also more likely to develop POD [92]. The ACS-NSQIP/AGS guidelines strongly recommend screening patients for depression prior to surgery [13]; simple tools, such as the short (15-item) version of the Geriatric Depression Scale, can be used for this purpose [93].

\section{Social support}

\begin{tabular}{lll}
\hline Statement & $\begin{array}{l}\text { Quality of } \\
\text { evidence }\end{array}$ & $\begin{array}{l}\text { Strength of } \\
\text { recommendation }\end{array}$ \\
\hline $\begin{array}{l}\text { It is recommended that the avail- } \\
\text { ability of family and social } \\
\text { support be investigated during } \\
\text { the preoperative assessment to }\end{array}$ & $\mathrm{A}$ \\
$\begin{array}{l}\text { allow planning of substitutive } \\
\text { support measures }\end{array}$ & \\
\hline
\end{tabular}

Social support predicts 30-day postoperative morbidity when included in a geriatric preoperative assessment [94]. Assessment of the patient's social support network is, therefore, recommended in the ACS-NSQIP/AGS guidelines [13]. If there is concern about insufficient family or social support, preoperative referral to a social worker should be considered [13].

\section{Intraoperative management}

\section{Positioning}

\begin{tabular}{|c|c|c|}
\hline Statement & $\begin{array}{l}\text { Quality of } \\
\text { evidence }\end{array}$ & $\begin{array}{l}\text { Strength of } \\
\text { recommendation }\end{array}$ \\
\hline $\begin{array}{l}\text { When positioning an older patient on } \\
\text { the operating table, we suggest that } \\
\text { attention be paid to conditions of the } \\
\text { skin (e.g., atrophy, injury) and the } \\
\text { musculoskeletal system (e.g., bone } \\
\text { deformities, joint stiffness, and pres- } \\
\text { ence of prostheses) }\end{array}$ & Low & B \\
\hline $\begin{array}{l}\text { It is recommended that positioning be } \\
\text { adjusted according to the patient's } \\
\text { problems, taking care to place } \\
\text { adequate padding at bony promi- } \\
\text { nences }\end{array}$ & Low & A \\
\hline
\end{tabular}

In older adults, the risk of peripheral nerve damage and pressure injuries resulting from malposition is increased by skin atrophy and decreased skin integrity [72]. Measures should, therefore, be taken to ensure proper positioning, taking into account musculoskeletal conditions such as kyphoscoliosis, and padding of bony prominences [36, 72]. Care should be taken when transferring the patient between their bed and the operating table, and when removing adherent items such as surgical dressings [36].

\section{Anesthesia}

\section{Type of anesthesia}

\begin{tabular}{lll}
\hline Statement & $\begin{array}{l}\text { Quality of } \\
\text { evidence }\end{array}$ & $\begin{array}{l}\text { Strength of } \\
\text { recommendation }\end{array}$ \\
\hline $\begin{array}{l}\text { It is recommended that the choice } \\
\text { of anesthesia (technique/drugs/ } \\
\text { dosage) be individualized based }\end{array}$ & Moderate & A \\
on the characteristics of the & \\
patient and the type of interven- & \\
tion, to reduce the incidence \\
of postoperative delirium and \\
facilitate recovery
\end{tabular}

There is insufficient evidence to recommend a single anesthetic plan for all older adults. The use of regional anesthesia as the primary modality may be beneficial in reducing perioperative mortality or major complications in patients undergoing surgery with intermediate or high cardiac risks [95]. In accordance with Enhanced Recovery After Surgery (ERAS) principles, combining neuraxial or regional techniques with general anesthesia results in less intra- and postoperative metabolic derangement and better control of postoperative pain.

\section{Dosage}

\begin{tabular}{lll}
\hline Statement & $\begin{array}{l}\text { Quality of } \\
\text { evidence }\end{array}$ & $\begin{array}{l}\text { Strength of } \\
\text { recommendation }\end{array}$ \\
\hline $\begin{array}{l}\text { We recommend dose adjustment } \\
\text { to avoid overdose, adverse } \\
\text { hemodynamic effects, or inad- } \\
\text { equate depth of narcosis }\end{array}$ & Moderate & A \\
$\begin{array}{l}\text { For induction and maintenance of } \\
\text { general anesthesia with propo- }\end{array}$ & Moderate & A \\
fol, we recommend that the \\
dosage be reduced by 20-50\% \\
in older patients \\
$\begin{array}{l}\text { For halogenated anesthetics, we } \\
\text { recommend that the minimal } \\
\text { alveolar concentration be calcu- } \\
\text { lated according to patient age }\end{array}$ \\
$\begin{array}{l}\text { Because the effect of anesthetics } \\
\text { on the central nervous system is }\end{array}$ & Moderate & A \\
age-dependent, we recommend \\
that halogenated and intrave- \\
nous anesthetic dosages be \\
modulated using an anesthesia \\
depth monitoring system
\end{tabular}


Age-related alterations in anesthetic pharmacokinetics and pharmacodynamics render older patients prone to unintentional overdosing [96], and appropriate dose adjustment is therefore essential. Particular care should be taken with hypnotic agents, because the dose required to induce anesthesia in older patients is lower, and the onset time longer, than in younger patients [97].

Propofol is suitable for older patients because of the rapid recovery time, and favorable adverse event profile. In patients older than 80 years, propofol is associated with less post-anesthetic cognitive impairment than other hypnotic agents [98]. However, the brain becomes more sensitive to the effects of propofol with age, and the elimination rate decreases linearly in patients older than 60 years; furthermore, geriatric patients are more sensitive to adverse effects of propofol, such as hypotension, compared with the general population $[99,100]$. Therefore, the dose should be reduced in older patients, particularly when administered with other induction agents $[98,99]$. Opioids have useful analgesic properties, but can cause delirium. Older patients have increased sensitivity to opioids, necessitating individual dose titration [85].

Depth of anesthesia monitors are recommended for patients at higher risk of adverse outcomes, irrespective of the anesthetic used [101]. With inhalational anesthetics, older patients require a lower minimal alveolar concentration (MAC) of anesthetic to achieve the same effect as in younger adults or children [102], and hence, it is recommended that the MAC for halogenated anesthetics should be calculated based on the patient's age [103]. If depth of anesthesia monitoring is unavailable, iso-MAC charts should be used to calculate the dose according to age-adjusted MAC values $[36,103]$.

\section{Depth of anesthesia monitoring}

\begin{tabular}{lll}
\hline Statement & $\begin{array}{l}\text { Quality of } \\
\text { evidence }\end{array}$ & $\begin{array}{l}\text { Strength of rec- } \\
\text { ommendation }\end{array}$ \\
\hline $\begin{array}{l}\text { During general anesthesia, we } \\
\text { recommend EEG-based monitor- }\end{array}$ & High & A \\
$\begin{array}{l}\text { ing to avoid excessive anesthesia } \\
\text { depth, which is associated with }\end{array}$ & & \\
$\begin{array}{l}\text { increased risk of postoperative } \\
\text { delirium }\end{array}$ & & A \\
$\begin{array}{l}\text { It is recommended that EEG-based } \\
\text { monitoring is extended to proce- } \\
\text { dures performed under sedation }\end{array}$ & High & \\
\hline
\end{tabular}

Depth of anesthesia monitoring to avoid episodes of deep anesthesia can significantly reduce POD in patients aged over 60 years under general anesthesia for surgery lasting more than $1 \mathrm{~h}[104,105]$. Therefore, guidelines from the UK recommend that depth of anesthesia should be monitored in all patients aged over 60 years $[77,78]$.

It is not possible to titrate anesthetics on the basis of on-line electroencephalography (EEG) [106]. By contrast, brain monitoring using processed EEG, such as the bispectral index (BIS), facilitates anesthetic titration and reduces episodes of deep levels of anesthesia [104, 107]. Observational studies suggest a significant association between anesthesia depth, as measured by BIS, and long-term ( $\geq 1$ year) mortality [108]. BIS monitoring may also prevent awareness phenomena related to light anesthesia levels, although these are rare events in older patients [109, 110].

Brain monitoring should also be extended to procedures performed under sedation. In a subgroup analysis of a randomized study, limiting sedation levels resulted in a reduction in POD in patients with low comorbid state [111]. However, the benefits of lighter sedation levels may be confounded by baseline comorbidities that increase the risk of delirium.

\section{Residual postoperative neuromuscular block}

\begin{tabular}{|c|c|c|}
\hline Statement & $\begin{array}{l}\text { Quality of } \\
\text { evidence }\end{array}$ & $\begin{array}{l}\text { Strength of } \\
\text { recommendation }\end{array}$ \\
\hline $\begin{array}{l}\text { In patients undergoing general } \\
\text { anesthesia with neuromuscular } \\
\text { block, we recommend that } \\
\text { neuromuscular function be } \\
\text { monitored quantitatively, and } \\
\text { its complete recovery (train-of- } \\
\text { four ratio }>0.9 \text { ) be facilitated } \\
\text { at the end of the intervention }\end{array}$ & Moderate & A \\
\hline $\begin{array}{l}\text { We recommend that residual } \\
\text { neuromuscular block always be } \\
\text { antagonized }\end{array}$ & Moderate & A \\
\hline $\begin{array}{l}\text { We recommend the use of sug- } \\
\text { ammadex when complete and } \\
\text { fast recovery of rocuronium- } \\
\text { induced neuromuscular block } \\
\text { is required }\end{array}$ & Moderate & A \\
\hline $\begin{array}{l}\text { We recommend the use of } \\
\text { sugammadex when anticho- } \\
\text { linesterases are ineffective for } \\
\text { reversing rocuronium-induced } \\
\text { neuromuscular block }\end{array}$ & Moderate & A \\
\hline
\end{tabular}

\section{Neuromuscular blocking agents}

Aging significantly affects the pharmacokinetics of neuromuscular blocking agents (NMBAs), particularly with drugs eliminated by hepatic or renal metabolism [112], and older patients are more sensitive to NMBAs than younger patients [113]. The intermediate-acting relaxants, vecuronium and rocuronium, which depend on end-organ elimination, may have a significantly prolonged duration of action in older 
patients, and appropriate dose adjustment is necessary [113]. Mivacurium action is also prolonged, due to age-related decreases in plasma acetylcholinesterase activity. Atracurium and cisatracurium, which are eliminated primarily by temperature-dependent, spontaneous Hoffman degradation, do not require dose adjustments in older patients, because the recovery time is almost identical to that in younger patients, although onset time may be delayed.

Monitoring the depth of neuromuscular blockade is essential in older patients to ensure appropriate dosing of NMBD during anesthesia and to avoid incomplete recovery from neuromuscular blockade after surgery. A train-of-four (TOF) $>0.9$ has been advocated as a criterion for adequate reversal of neuromuscular blockade [113, 114].

\section{Neuromuscular blockade reversal in older patients}

Complications related to postoperative residual curarization (PORC) are more frequent in older patients than in younger patients [109]. Furthermore, pharyngeal function, which is often impaired in geriatric patients, may be worsened by PORC, possibly resulting in postoperative aspiration-induced pneumonia [115]. PORC is strongly linked to inadequate reversal of neuromuscular blockade, and hence, accurate dosing of NMBAs, vigilant monitoring of neuromuscular blockage, and appropriate administration of reversal agents, are essential.

The duration of action of the cholinesterase inhibitors neostigmine and pyridostigmine is prolonged in aged patients [116, 117], whereas this is not true for edrophonium [118]. Hence, neostigmine and pyridostigmine are preferable to edrophonium for reversal of neuromuscular blockade in older patients, because their prolonged duration of action can counteract age-related increases in the duration of action of NMBAs.

Sugammadex binds to aminosteroidal NMBAs (rocuronium and vecuronium), forming a complex that is primarily excreted by the kidneys. Decreases in kidney function reduce sugammadex clearance, and prolong its half-life and duration of action [119]. Sugammadex is significantly faster than neostigmine in reversing neuromuscular blockade, and is more likely to be associated with higher TOF values and a lower risk of PORC [120]. Reversal of NMB with sugammadex is rapid, although slightly slower than in younger adults [119], especially with low-dose sugammadex [121].

\section{Temperature control}

\begin{tabular}{lll}
\hline Statement & $\begin{array}{l}\text { Quality of } \\
\text { evidence }\end{array}$ & $\begin{array}{l}\text { Strength of } \\
\text { recommendation }\end{array}$ \\
\hline $\begin{array}{l}\text { We recommend body-temperature } \\
\text { monitoring and active warming of } \\
\text { the patient, preferably with a forced- }\end{array}$ & High & A \\
$\begin{array}{l}\text { air system, during the pre-, intra-, } \\
\text { and postoperative periods }\end{array}$ & \\
$\begin{array}{l}\text { If forced-air heating is only partially } \\
\text { efficacious (e.g., during prolonged } \\
\text { open abdominal surgery), we sug- } \\
\text { gest that warm intravenous fluids be }\end{array}$ & & B \\
administered & & \\
\hline
\end{tabular}

Most anesthetics can inhibit thermoregulation, resulting in perioperative hypothermia $\left(<36.0{ }^{\circ} \mathrm{C}\right)$. Older patients are particularly predisposed to hypothermia due to altered thermoregulation resulting from decreases in muscle mass, metabolic rate, and vascular reactivity [72]. Active warming procedures are, therefore, necessary to maintain normothermia. These may include covering the patient's head and body, increasing the ambient room temperature, warming intravenous and irrigating solutions, and applying external warming devices.

Core temperature should be monitored in operations lasting more than $30 \mathrm{~min}$, and warming should be used in older patients [72]. A forced-air warming system set at $42{ }^{\circ} \mathrm{C}$ is the most effective means of rewarming older patients with postoperative hypothermia [122], but a prewarmed infusion could also reduce the incidence of perioperative hypothermia and improve outcomes in geriatric patients [123].

\section{Fluid and electrolyte balance}

\begin{tabular}{lll}
\hline Statement & $\begin{array}{l}\text { Quality of } \\
\text { evidence }\end{array}$ & $\begin{array}{l}\text { Strength of } \\
\text { recommendation }\end{array}$ \\
\hline $\begin{array}{l}\text { We recommend adequate monitor- } \\
\text { ing to maintain a "near-zero" }\end{array}$ & High & A \\
fluid balance & & \\
\hline
\end{tabular}

Appropriate use of intravenous fluids is important to prevent hypovolemia or dehydration in geriatric surgical patients. Multiple international guidelines allow unrestricted intake of clear fluids up to $2 \mathrm{~h}$ before elective surgery [124]. However, some recent guidelines advocate more restrictive fluid management [125]; the term "zero balance" has been introduced to describe a restrictive regimen aiming to avoid postoperative fluid retention [126]. Concerns remain about impaired organ perfusion with this restrictive approach. In one study, 
patients managed with a restrictive fluid approach had a significantly higher risk of acute kidney injury (AKI) than those receiving liberal fluid administration [127].

In ERAS guidelines, the preoperative goal is to prepare a hydrated, euvolaemic patient by avoiding routine mechanical bowel preparation and encouraging patients to drink clear liquids up to $2 \mathrm{~h}$ before induction of anesthesia. The intra-operative goal is to achieve a 'zero' fluid balance after uncomplicated surgery; goal-directed fluid therapy (GDT) is recommended for poorly prepared or high-risk patients or those undergoing more complex surgery. The postoperative goal is early transition from intravenous to oral fluid therapy [125]: GDT reduces postoperative mortality, compared with standard hemodynamic therapy, even in high-risk patients [128]. Recent Italian guidelines [129] recommend perioperative GDT to reduce morbidity, and possibly mortality in high-risk patients.

\section{Blood transfusion}

\begin{tabular}{lll}
\hline Statement & $\begin{array}{l}\text { Quality of } \\
\text { evidence }\end{array}$ & $\begin{array}{l}\text { Strength of } \\
\text { recommendation }\end{array}$ \\
\hline $\begin{array}{l}\text { We recommend that transfusion in } \\
\text { geriatric patients follows a restric- } \\
\text { tive transfusion strategy (red blood } \\
\text { cell transfusion threshold: Hb }<8 \mathrm{~g} /\end{array}$ & High & $\mathrm{A}$ \\
$\mathrm{dl}$ ) & & \\
$\begin{array}{l}\text { We recommend red blood cell } \\
\text { transfusion when symptoms of }\end{array}$ & High & $\mathrm{A}$ \\
$\begin{array}{l}\text { intraoperative hypoxia and/or } \\
\text { lactic acidosis and hemorrhage are } \\
\text { present, regardless of the severity } \\
\text { of anemia }\end{array}$ & & \\
\hline
\end{tabular}

The patient's bleeding tendency must be assessed before surgery, irrespective of medical history or medication use and surgery scheduled according to optimization of erythropoiesis. Intraoperative PBM includes: meticulous hemostasis and surgical technique; cell salvage; appropriate use of drugs and hemostatic agents; point-of-care tests for bleeding; and restrictive transfusion thresholds [58].

The standard treatment for severe perioperative anemia is transfusion of allogenic red blood cells (RBC): more than $50 \%$ of such transfusions are given to old and frail patients [130]. Compensatory mechanisms for anemia are severely impaired in older patients, and this may result in greater vulnerability to anemia-related ischemic events and perioperative complications [54]. In the absence of specific clinical conditions reducing tolerance of anemia, restrictive rather than liberal, transfusion strategies are recommended [131]. In a study of older adults (age $\geq 70$ years) undergoing hip fracture surgery, a restrictive transfusion strategy was found to be safe, and was associated with fewer cardiovascular complications but more transfusions, compared with a more liberal regimen [132]. The LIBERAL trial is currently evaluating the benefits of liberal transfusion strategies in older surgical patients [133].

RBC transfusions are always indicated if the hemoglobin concentration is $<6 \mathrm{~g} / \mathrm{dl}$, and may be indicated in patients with concentrations between 6 and $10 \mathrm{~g} / \mathrm{dl}$. RBC transfusions are not indicated in adult, hemodynamically stable, patients with hemoglobin $>7 \mathrm{~g} / \mathrm{dl}$, although a threshold of $8 \mathrm{~g} / \mathrm{dl}$ may be applied to patients undergoing orthopedic or cardiac surgery, and patients with cardiovascular disease [58]. In a study in patients aged $\geq 65$ years undergoing major noncardiac surgery, intraoperative blood transfusion was associated with decreased 30-day postoperative mortality, compared with patients who did not receive transfusions, among the subgroups with substantial operative blood loss or low preoperative hematocrit $(<24 \%)$. Conversely, transfusion was associated with increased mortality in patients with preoperative hematocrits between 30 and $35.9 \%$ or $<500 \mathrm{ml}$ blood loss during surgery [134].

\section{Minimally invasive surgery}

\begin{tabular}{lll}
\hline Statement & $\begin{array}{l}\text { Quality of } \\
\text { evidence }\end{array}$ & $\begin{array}{l}\text { Strength of } \\
\text { recommendation }\end{array}$ \\
\hline $\begin{array}{l}\text { We suggest using minimally } \\
\text { invasive techniques in older } \\
\text { patients, to reduce the endocrine/ }\end{array}$ & Moderate & B \\
metabolic response to stress and & & \\
improve postoperative outcomes & & \\
During laparoscopy, we recom- & Moderate & A \\
mend & & \\
Avoiding exaggerated or pro- & \\
longed Trendelenburg or anti- & \\
Trendelenburg positions & \\
Avoiding unjustified prolongation & \\
of surgical times & \\
Using the lowest possible & \\
intraperitoneal pressure & \\
(<12 mmHg), to minimize the & \\
negative cardiovascular and & \\
respiratory effects caused by & \\
pneumoperitoneum & \\
Administering deep neuromuscu- \\
lar blockade, to allow the use of \\
low working pressures
\end{tabular}

Where feasible, laparoscopic surgery is becoming standard treatment for many common pathologies that disproportionately affect older patients. Benefits of laparoscopy include decreased postoperative pain, shorter hospitalizations, improved cosmesis, and a quicker return to normal activity. However, laparoscopy may be technically challenging, 
and imposes specific physiologic demands on older patients [135]. In a study in colorectal cancer patients aged $\geq 80$ years, laparoscopic surgery was associated with less blood loss, fewer postoperative complications, and shorter hospitalizations, than open surgery [136]. A recent systematic review found that short-term outcomes after laparoscopic surgery for colorectal cancer were generally similar in older and younger patients, although the overall complication rate was slightly but significantly higher in older patients [137].

Recent years have seen the introduction of robot-assisted surgical techniques. These techniques appear to be safe in older patients, with no increased risk of death or morbidity compared with younger patients [138]. Nevertheless, their use should depend on the specific history and comorbidities of the individual patient [138].

\section{Postoperative care}

\section{General strategies for optimizing postoperative recovery}

\begin{tabular}{lll}
\hline Statement & $\begin{array}{l}\text { Quality of } \\
\text { evidence }\end{array}$ & $\begin{array}{l}\text { Strength of } \\
\text { recommendation }\end{array}$ \\
\hline $\begin{array}{l}\text { In the postoperative period, we } \\
\text { recommend: }\end{array}$ & Moderate & $\mathrm{A}$ \\
- Optimal postoperative pain control & \\
- Early mobilization and walking & \\
- Early resumption of feeding & \\
- Conservation of the sleep-wake & \\
rhythm & \\
- Reducing use of nasogastric tube & \\
and bladder catheters & \\
- Antithrombotic prophylaxis & \\
We recommend the use of Enhanced & Moderate & A \\
Recovery Pathways for older & & \\
patients, according to the type of & & \\
surgery performed &
\end{tabular}

ERAS protocols aimed at reducing postoperative morbidity cover the whole perioperative period [139]. This multidisciplinary approach decreases length of stay and healthcare costs by better postoperative pain and nausea control, integration of preoperative, intraoperative, and postoperative care, and education to enable patients and families to participate in care. In a systematic review of 24 studies, the ERAS items that most strongly predicted shorter hospitalization and lower morbidity were: absence of a nasogastric tube; early mobilization, oral nutrition, and removal of the urinary catheter; and use of nonopioid analgesia [140]. Importantly, reduction in surgical stress through ERAS appears to be particularly effective in reducing complications and supporting recovery in older and frail patients [141, 142].

\section{Postoperative delirium}

\begin{tabular}{|c|c|c|}
\hline Statement & $\begin{array}{l}\text { Quality of } \\
\text { evidence }\end{array}$ & $\begin{array}{l}\text { Strength of } \\
\text { recommendation }\end{array}$ \\
\hline $\begin{array}{l}\text { It is recommended that preven- } \\
\text { tion, recognition and treatment of } \\
\text { postoperative delirium must be an } \\
\text { objective of the multidisciplinary } \\
\text { team }\end{array}$ & Moderate & A \\
\hline $\begin{array}{l}\text { We recommend that patients at risk } \\
\text { for POD be monitored with vali- } \\
\text { dated diagnostic tools such as the } \\
\text { CAM or } 4 \text { AT, starting when they } \\
\text { wake from anesthesia and continu- } \\
\text { ing for } 5 \text { days thereafter }\end{array}$ & Moderate & A \\
\hline
\end{tabular}

POD assessment should be performed, while the patient is still in the recovery room, and repeated over 5 days. Validated screening tools, such as the 4AT, and the CAM [143] and its variant for use in intensive care (CAM-ICU), facilitate recognition of POD: diagnosis rates are almost $100 \%$ when screening tools are used, but low in their absence. We, therefore, recommend using POD screening tools in the postoperative period [144]. However, CAM requires specific training to ensure reliability of diagnosis, whereas the 4AT can be used in various care settings without specific training [147]. It also allows evaluation of patients who are unable to complete more detailed cognitive tests because of drowsiness or agitation. We, therefore, recommend that the 4AT is included in the preadmission assessment of older surgical patients, and if possible incorporated into nursing routines [144].

An Italian intersociety consensus has highlighted recommendations for the prevention, diagnosis, and treatment of delirium in older hospitalized patients [145]. All patients with delirium should receive an individualized treatment plan, including identification of underlying acute diseases and other clinical conditions that may lead to delirium. Medication reconciliation, early mobilization, promotion of physiologic sleep-wake rhythm, maintenance of adequate nutrition and hydration, and the provision of visual and auditory aids, should be implemented [78]. This requires a multidisciplinary, coordinated, approach, coordinated where possible by the geriatrician. It is also important to recognize the potential role of family and caregivers in supporting the patient. Flexibility of visiting hours, and the use of investigative tools to determine the patient's needs and preferences, should be encouraged [146].

Cognitive changes after anesthesia also include postoperative neurocognitive disorders. Specific risk factors for such disorders should be evaluated in susceptible patients $[148,149]$. 


\section{Postoperative nausea and vomiting}

\begin{tabular}{lll}
\hline Statement & $\begin{array}{l}\text { Quality of } \\
\text { evidence }\end{array}$ & $\begin{array}{l}\text { Strength of } \\
\text { recommendation }\end{array}$ \\
\hline $\begin{array}{l}\text { Because of the high risk (e.g., of } \\
\text { aspiration pneumonia), we recom- }\end{array}$ & Low & A \\
mend the use of adequate prophy- & & \\
$\begin{array}{l}\text { laxis against postoperative nausea } \\
\text { and vomiting, and semi-Fowler's } \\
\text { decubitus position }\end{array}$ & & \\
\hline
\end{tabular}

Postoperative nausea and vomiting can cause fear and anxiety before surgery, and can result in poor patient satisfaction, prolonged time in the postanesthesia care unit, and unplanned hospital admission in surgical outpatients. Although younger age $(<50$ years) is a primary risk factor for PONV, surgical factors and anesthetic techniques increase the risk, even in low-risk populations. In addition, approximately $15 \%$ of older patients are affected by dysphagia, and this may increase to $50 \%$ in those with neurologic disease; PONV in older patients with postoperative dysphagia can increase the risk of aspiration pneumonia [150].

Risk factors for PONV should be assessed in all older surgical patients. Patients at moderate or high risks should receive appropriate prophylactic interventions and risk mitigation strategies, according to guidelines and local practice [72].

\section{Postoperative pain}

\begin{tabular}{lll}
\hline Statement & $\begin{array}{l}\text { Quality of } \\
\text { evidence }\end{array}$ & $\begin{array}{l}\text { Strength of } \\
\text { recommendation }\end{array}$ \\
\hline $\begin{array}{l}\text { Personalized prevention and treat- } \\
\text { ment of postoperative pain are } \\
\text { mandatory. We recommend a }\end{array}$ & Low & A \\
multimodal approach or, when \\
possible, locoregional or plane & & \\
blocks (e.g., TAP block) & & \\
$\begin{array}{l}\text { We suggest encouraging use of the } \\
\text { non-pharmacological components } \\
\text { of the multimodal approach }\end{array}$ & Low & B \\
\hline
\end{tabular}

Inadequate analgesia for older surgical patients contributes to postoperative morbidity, including delirium, cardiorespiratory complications, and failure to mobilize. However, postoperative pain is poorly assessed and treated in older patients, particularly those with cognitive impairment [36]. Pain can be assessed using the numerical rating scale, visual analogic scale, or verbal rating scale in patients with mildto-moderate cognitive impairment; we recommend the use of specific scales (PAINAD, NOPPAIN, and Doloplus-2) for those with severe cognitive disorders [145].

Analgesic plans for older adults should be multimodal to avoid adverse effects of opioid analgesics and anxiolytics
[151]. Non-pharmacological methods (e.g., positioning, acupuncture, music therapy, massage) are important adjunctive analgesic modalities [69]. Benefits of this approach include better pain scores, reduced sedation frequency, and reduced usage of opioid medications, compared with systemic opioids alone [72]. Paracetamol is safe and should be considered first-line pain therapy, with only minor concerns about dosage ( $<3 \mathrm{~g} /$ day in older patients) and the risk of renal insufficiency, compared with the general population. If paracetamol is ineffective, NSAIDs should be used at the lowest possible dose and for the shortest possible duration, with concomitant proton pump inhibitor therapy and monitoring for gastric and renal damage. Older patients are more sensitive to adverse effects of opioids and NSAIDs, and more prone to postoperative morbidity. The combination of opioid-free general anesthesia with neuraxial or regional local anesthesia, according to ERAS principles, is indicated in this situation [148]. Morphine is an effective analgesic for moderate or severe pain, but should be administered cautiously, particularly in patients with poor renal or respiratory function, cognitive impairment, or both [36]. Meperidine has consistently been associated with an increased risk of POD in older surgical patients, but the incidence of POD and cognitive decline with this agent appear to be similar to those seen with more frequently used postoperative opioids such as morphine, fentanyl, or hydromorphone [152].

Regional or neuraxial techniques, such as transversus abdominus plane (TAP) block, can decrease the need for intraoperative or postoperative systemic narcotics [153]. Patient-controlled analgesia can be considered in appropriate patients.

\section{Postoperative pulmonary complications}

\begin{tabular}{lll}
\hline Statement & $\begin{array}{l}\text { Quality of } \\
\text { evidence }\end{array}$ & $\begin{array}{l}\text { Strength of } \\
\text { recommendation }\end{array}$ \\
\hline $\begin{array}{l}\text { We recommend periodic evaluation } \\
\text { of oxygen saturation and res- } \\
\text { piratory rate in the postoperative } \\
\text { period }\end{array}$ & Moderate & A \\
$\begin{array}{l}\text { We recommend that arterial blood } \\
\text { gas analysis be used when condi- } \\
\text { tions interfere with percutaneous }\end{array}$ & Moderate & A \\
$\begin{array}{l}\text { oximetry (e.g., shivering, tremor, } \\
\text { cold skin, hyperthermia, hypoten- } \\
\text { sion, advanced heart failure, high } \\
\text { fever, atrial fibrillation, or other } \\
\text { arrhythmias) }\end{array}$ & \\
$\begin{array}{l}\text { We suggest that older patients } \\
\text { should be treated with lung expan- } \\
\text { sion techniques, such as deep } \\
\text { breathing exercises, incentive }\end{array}$ & \\
$\begin{array}{l}\text { spirometry or, when indicated, } \\
\text { with non-invasive ventilation }\end{array}$ & \\
\hline
\end{tabular}


Postoperative pulmonary complications (PPCs) increase postoperative mortality, and health care costs [72, 154]. Older age may be an independent predictor of PPCs [155]. Compared with patients under 50 years of age, the incidence of PPCs is almost fivefold higher in those aged $>80$ years [47]. Hence, periodic evaluation of oxygen saturation, arterial blood gases, and respiratory rate is recommended in older patients.

In addition to optimization of pulmonary status during the preoperative and intraoperative periods, several postoperative strategies can be used to prevent PPCs in older patients, including screening for signs and symptoms of dysphagia [155], incentive spirometry, chest physical therapy, and deep breathing exercises $[44,49]$. Monitoring of vital signs in the post-anesthetic setting is essential to identify patients at potential risk of postoperative respiratory failure [156]. Incentive spirometry is widely used to prevent PPCs, although clinical effectiveness data are limited, and standardized protocols are lacking $[157,158]$.

\section{Postoperative cardiovascular complications}

\begin{tabular}{lll}
\hline Statement & $\begin{array}{l}\text { Quality of } \\
\text { evidence }\end{array}$ & $\begin{array}{l}\text { Strength of rec- } \\
\text { ommendation }\end{array}$ \\
\hline $\begin{array}{l}\text { To prevent postoperative cardiac } \\
\text { complications, we recommend } \\
\text { monitoring (continuously in } \\
\text { selected cases) and maintenance }\end{array}$ & High & A \\
of cardiovascular measures (e.g., & & \\
heart rate, arterial pressure) & & \\
within baseline values & High & B \\
$\begin{array}{l}\text { We suggest the use of graduated } \\
\text { compression stockings or inter- } \\
\text { mittent pneumatic compression, }\end{array}$ & & \\
when indicated & & \\
\hline
\end{tabular}

Age has not consistently been found to be an independent predictor of perioperative cardiac risk, although perioperative mortality following acute myocardial infarction is higher in older than in young patients [159]. Strategies to reduce cardiac risk in older patients include the use of beta blockers and statins, perioperative blood pressure control, and preoperative ECG [159].

Thromboprophylaxis is usually based on low-molecularweight heparins. Graduated compression stockings or intermittent pneumatic compression are a valuable alternative in selected situations, such as neurosurgery, and a useful complement in others, including some orthopedic procedures. Use of such measures in older surgical patients is endorsed in current ESA guidelines [43].

\section{Acute kidney injury}

\begin{tabular}{lll}
\hline Statement & $\begin{array}{l}\text { Quality of } \\
\text { evidence }\end{array}$ & $\begin{array}{l}\text { Strength of rec- } \\
\text { ommendation }\end{array}$ \\
\hline $\begin{array}{l}\text { For prevention of renal damage, } \\
\text { we recommend that adequate }\end{array}$ & High & A \\
$\begin{array}{l}\text { hydration be maintained, and } \\
\text { hypovolemia and/or hypotension } \\
\text { be avoided }\end{array}$ & \\
$\begin{array}{l}\text { We recommend caution in the use } \\
\text { of potentially nephrotoxic drugs } \\
\text { or drug combinations with a high } \\
\text { risk of nephrotoxicity, and in the } \\
\text { administration of contrast media } \\
\text { for radiological procedures }\end{array}$ & A & \\
\hline
\end{tabular}

In older patients, pre-existing CKD, male gender, diabetes mellitus, heart failure, and surgery are major risk factors for AKI, and both CKD and AKI are independently associated with poor surgical outcomes. The optimal approach to preventing AKI in older surgical patients is unknown, but perioperative close monitoring of fluid balance, avoidance of nephrotoxic drugs, appropriate adjustment of renally excreted drugs, careful use of contrast media, and prompt treatment of sepsis are appropriate in all older patients. Because relatively small changes in serum creatinine can predict or define AKI [160], estimation of GFR should be available prior to surgery to facilitate the early detection of AKI.

\section{Urinary tract infection}

\begin{tabular}{lll}
\hline Statement & $\begin{array}{l}\text { Quality of } \\
\text { evidence }\end{array}$ & $\begin{array}{l}\text { Strength of rec- } \\
\text { ommendation }\end{array}$ \\
\hline $\begin{array}{l}\text { We recommend that urinary } \\
\text { catheters be used only when } \\
\text { essential, and be removed as soon } \\
\text { as possible }\end{array}$ & High & A \\
$\begin{array}{l}\text { We recommend to adopt strategies } \\
\text { to prevent urinary tract infections } \\
\text { before, during, and after insertion } \\
\text { of a urinary catheter }\end{array}$ & High & A \\
$\begin{array}{l}\text { We do not recommend comple- } \\
\text { mentary strategies (such as the } \\
\text { use of alpha-blockers in men) } \\
\begin{array}{l}\text { to promote spontaneous urinary } \\
\text { function after catheter removal }\end{array}\end{array}$ & & \\
\hline
\end{tabular}

Older adults are at particular risk for urinary tract infection (UTI), particularly if immobilized [72]. Guidelines for the prevention and management of UTI recommend limited use of urinary catheters, aseptic insertion of catheters, and maintenance of a closed drainage system [161]. Clinical evidence 
suggests that early removal of urinary catheters, whenever possible, is related to a lower risk of urinary infection and faster hospital discharge [72, 162].

\section{Nutrition and liquid balance}

\begin{tabular}{lll}
\hline Statement & $\begin{array}{l}\text { Quality of } \\
\text { evidence }\end{array}$ & $\begin{array}{l}\text { Strength of } \\
\text { recommendation }\end{array}$ \\
\hline $\begin{array}{l}\text { It is recommended that older patients } \\
\text { undergo daily assessment of caloric } \\
\text { intake and water balance }\end{array}$ & Moderate & A \\
$\begin{array}{l}\text { We recommended that swallowing } \\
\text { should be evaluated, and the pres- }\end{array}$ & Moderate & A \\
ence of oral lesions excluded in \\
patients with signs and symptoms \\
$\begin{array}{l}\text { of dysphagia or a history of aspira- } \\
\text { tion pneumonia }\end{array}$ & & \\
$\begin{array}{l}\text { We suggest that all older patients are } \\
\text { seated during meals and for an hour } \\
\text { after eating }\end{array}$ & Moderate & B \\
$\begin{array}{l}\text { It is recommended that nutritional } \\
\text { supplementation be given in } \\
\text { patients with malnutrition or inad- }\end{array}$ & Moderate & A \\
equate nutrition & & \\
$\begin{array}{l}\text { It is recommended that dental pros- } \\
\text { theses, if used, are readily available } \\
\text { and easily accessible }\end{array}$ & Moderate & A \\
\hline
\end{tabular}

Several studies have highlighted the association between malnutrition and adverse outcomes in older patients [163], and systematic reviews have reported that early feeding in selected patients is not harmful [164-166]. Thus, nutritional support should be continued from the preoperative period, or instituted early after surgery, to improve wound healing and recovery [36]. Enteral nutrition is associated with better outcomes (shorter hospitalization, reductions in incidence or severity of complications, and decreased healthcare costs), compared with parenteral nutrition [166].

Oral feeding ability and aspiration risk should be assessed daily in older patients. A dietary consultation should be initiated, and a formal swallowing assessment performed if indicated [72]. During oral feeding, the head of the bed should be elevated at all times, and the patient should be sitting upright while eating and for $1 \mathrm{~h}$ after each meal, to prevent aspiration [72]. In addition, fluid status should be evaluated daily, with recording of input/output or body weight, for at least the first 5 postoperative days [72].

Older persons undergoing hip fracture surgery are generally at risk of malnutrition due to the acute trauma and surgery-related anorexia and immobility. Voluntary oral intake in the postoperative phase is often inadequate in such patients, and hence, rapid deterioration of nutritional status and impaired recovery are common [166]. Thus, the ESPEN guidelines for geriatric patients recommend that older patients with hip fracture should be offered oral nutritional supplements postoperatively, to reduce the risk of complications [166]. Such nutritional support should be part of an individually tailored, multimodal, and multidisciplinary intervention to ensure adequate dietary intake, improve clinical outcomes, and maintain quality of life [166].

Early tube feeding is recommended for patients who are unable to take oral supplements, such as those undergoing major head and neck or neurosurgical procedures, or patients who are unable to take $50 \%$ of their caloric needs orally for more than 7 days [167].

\section{Pressure ulcers}

\begin{tabular}{lll}
\hline Statement & $\begin{array}{l}\text { Quality of } \\
\text { evidence }\end{array}$ & $\begin{array}{l}\text { Strength of } \\
\text { recommendation }\end{array}$ \\
\hline $\begin{array}{l}\text { Strategies to prevent and treat pres- } \\
\text { sure injuries are recommended in } \\
\text { patients at risk }\end{array}$ & Moderate & A \\
\hline
\end{tabular}

Hospitalized older patients, particularly frail patients with hip fractures [168], are at high risk of pressure ulcers. Health care teams should, therefore, assess the risk of pressure ulcers in all older postoperative patients, and should implement multimodal interventions to prevent and treat pressure ulcers, especially in at-risk patients [72].

\section{Surgical site infections}

\begin{tabular}{lll}
\hline Statement & $\begin{array}{l}\text { Quality of } \\
\text { evidence }\end{array}$ & $\begin{array}{l}\text { Strength of } \\
\text { recommendation }\end{array}$ \\
\hline $\begin{array}{l}\text { We recommend guideline-consistent } \\
\text { antimicrobial prophylaxis in older }\end{array}$ & Moderate & A \\
patients, considering antibiotic & & \\
pharmacodynamics and pharma- & & \\
cokinetics to avoid overdoses and & & \\
drug-related adverse events & & \\
\hline
\end{tabular}

Surgical site infections (SSIs) are associated with delayed wound healing, prolonged hospital stays, increased use of antibiotics, unnecessary pain, and (rarely) death. Antibiotic prophylaxis is a principal strategy for preventing SSIs, but reductions in SSIs can also be achieved by implementing multidisciplinary, hospital-wide, measures such as bowel preparation, skin preparation, disinfection and hygiene, maintenance of normothermia during surgery, and glycemic control [169].

In older patients, it is important to choose the antimicrobial agent according to the susceptibility profile of colonizing bacteria. Particular attention should also be paid to the dosing regimen, because the relationship between appropriately dosed preoperative antibiotics and reduced risk of SSIs is well 
established. However, older patients may have renal impairment necessitating dose adjustment [60, 170]. Guidelines recommend that preoperative antibiotics should be given within $60 \mathrm{~min}$ before surgical incision, and that the choice of agent should be based on the nature of the surgical procedure, risk factors, and the hospital's unique pathogen profile [171].

\section{Hyperglycemia and glucose management}

\begin{tabular}{lll}
\hline Statement & $\begin{array}{l}\text { Quality of } \\
\text { evidence }\end{array}$ & $\begin{array}{l}\text { Strength of } \\
\text { recommendation }\end{array}$ \\
\hline $\begin{array}{l}\text { We recommend careful and pro- } \\
\text { longed assessment of blood glucose } \\
\text { in older patients with or without } \\
\text { diabetes }\end{array}$ & Moderate & A \\
$\begin{array}{l}\text { Insulin is the treatment of choice for } \\
\text { the management of hyperglycemias }\end{array}$ & \\
$\begin{array}{l}\text { We suggest that blood glucose values } \\
\text { up to 180 mg/dl are acceptable in } \\
\text { critical postoperative patients }\end{array}$ & Moderate & B \\
\hline
\end{tabular}

In older patients, postoperative hyperglycemia is associated with poor wound healing, SSI, acute complications (fluid and electrolyte disorders, acute renal failure), longer hospitalization, and death [172]. Glucose management is, therefore, an important aspect of postoperative care, and insulin is the drug of choice to treat postoperative hyperglycemia [173-175].

\section{Hospital discharge and continuity of care}

\begin{tabular}{lll}
\hline Statement & $\begin{array}{l}\text { Quality } \\
\text { of evidence }\end{array}$ & $\begin{array}{l}\text { Strength of rec- } \\
\text { ommendation }\end{array}$ \\
\hline $\begin{array}{l}\text { During the surgical planning, } \\
\text { we recommend evaluating } \\
\text { the probability of the patient } \\
\text { returning home at the end of }\end{array}$ & Moderate & A \\
the hospital stay & \\
For patients with functional & Moderate & A \\
deterioration and/or weak & & \\
social networks, we recom- & & \\
mend that the discharge plan, \\
including outpatient visits and \\
medications, should be organ- \\
ized in advance in collabora- \\
tion with the geriatrician; \\
ideally, a Geriatric Evaluation \\
Unit should be available \\
\hline
\end{tabular}

\begin{tabular}{lll}
\hline Statement & $\begin{array}{l}\text { Quality } \\
\text { of evidence }\end{array}$ & $\begin{array}{l}\text { Strength of rec- } \\
\text { ommendation }\end{array}$ \\
\hline $\begin{array}{l}\text { Before hospital discharge, we } \\
\text { recommend re-evaluating } \\
\text { and adjusting drug therapy }\end{array}$ & Moderate & A \\
according to home therapy, & \\
the surgery performed, & & \\
comorbidities, and any new & & \\
pathological changes & & \\
We recommend that the patient & Moderate & \\
and caregiver be provided & & \\
with resources to deal with & & \\
problems that may arise at & & \\
home, and with patient man- & \\
agement contacts and refer- & \\
ences (telephone/e-mail) & \\
\hline
\end{tabular}

The question of where the patient can receive the best possible support after discharge should be considered throughout the perioperative period. The lack of an appropriate discharge and transition plan makes early readmission more likely, and may impair functional status and quality of life [176]. It is essential to establish an organizational framework that incorporates: appropriate assessment of the patient's clinical, social and care status; recognition of patients', relatives' and caregivers' expectations; formal planning and coordination of discharge; good knowledge of transitional management programs; and communication between different care settings [177].

Changes to medication frequently occur during hospitalization of older adults, and prompt review within primary care is essential following discharge [178, 179].

CGA of frail geriatric patients can reduce the risk of readmission when performed immediately before hospital discharge or on arrival in community settings. This should include targeting criteria to identify vulnerable patients, a multidimensional assessment program, comprehensive discharge planning, and home follow-up.

Some frail patients may develop a transient period of health vulnerability following hospitalization, known as the post-hospital syndrome (PHS) [180]. PHS is characterized by the risk of early re-hospitalization due to physiologic stressors resulting from the initial admission, including disruption in sleep-wake cycles, inadequate pain control, deconditioning, and changes in nutritional status. Patients hospitalized within 90 days of elective surgery are at increased risk of PHS [181].

Geriatric patients, especially if frail, often need prolonged hospitalization, or care in intermediate care facilities, before returning home. For some patients, worsening health and functional status make it impossible to return home. In a study of surgical patients aged $\geq 65$ years, $30 \%$ were discharged to an institutional care facility; the strongest predictors of institutionalization were a TUG time $\geq 15 \mathrm{~s}$ and 
functional dependence [182]. Discharge to residential care, and inability to maintain independence after surgery, may be unacceptable to many older patients [183]. Anticipating which adults will require discharge to care facilities is important for preoperative counseling and care planning for both patients and caregivers. Before surgery, patients and surgeons should discuss clearly what they hope to achieve with the intervention, and what secondary strategy should be adopted if these objectives are not achieved or complications occur. Furthermore, all members of the multidisciplinary team should take into consideration advance directives such as "do not resuscitate" orders. The patient's autonomy must always be respected, and it should not be assumed that the patient will accept all postoperative treatments should complications occur [184].

\section{Conclusions}

These recommendations should facilitate the multidisciplinary management of older surgical patients, integrating the expertise of surgeons, anesthetists, geriatricians, and other specialists and health care professionals. These roles might vary according to the phase and setting of care and the patient's condition.

A number of general statements can be made about the perioperative care of geriatric surgical patients. First, prehabilitation and ERAS protocols are recommended in all older candidates for elective surgery. Second, continuity of care is the hallmark of optimal care, and this requires early planning of the expected needs, final location of care and transition strategies for problematic cases. Finally, for medium- to high-risk patients, implementation of CGA and associated care should be considered in terms of the relative costs and benefits, rather than cost alone.

Acknowledgements The authors would like to thank Dr. Luigia Scudeller for assistance with methodology. Medical writing and editorial assistance in the preparation of this paper were provided by Michael Shaw Ph.D. (MScript Ltd, Hove, UK), on behalf of Editamed srl, Torino, Italy.

Funding This work, including travel and meeting expenses, was supported by an unrestricted grant from MSD Italia Srl. The sponsor had no role in selecting the participants, reviewing the literature, defining consensus statements, drafting or reviewing the paper, or in the decision to submit the manuscript. All views expressed are solely those of the authors.

\section{Compliance with ethical standards}

Conflict of interest The authors declare that they have no conflict of interest.

Ethical approval Not applicable.
Statement of human and animal rights Not applicable.

Informed consent Not applicable.

Open Access This article is licensed under a Creative Commons Attribution 4.0 International License, which permits use, sharing, adaptation, distribution and reproduction in any medium or format, as long as you give appropriate credit to the original author(s) and the source, provide a link to the Creative Commons licence, and indicate if changes were made. The images or other third party material in this article are included in the article's Creative Commons licence, unless indicated otherwise in a credit line to the material. If material is not included in the article's Creative Commons licence and your intended use is not permitted by statutory regulation or exceeds the permitted use, you will need to obtain permission directly from the copyright holder. To view a copy of this licence, visit http://creativecommons.org/licenses/by/4.0/.

\section{References}

1. Demographic Indicators (2019) Estimates for the year 2018. Italian National Institute of Statistics (Istituto Nazionale di Statistica; Istat). https://www.istat.it/it/files//2019/02/Indicatoridemog rafici2018_EN.pdf. Accessed 26 Feb 2020

2. Moyet J, Deschasse G, Marquant B et al (2019) Which is the optimal orthogeriatric care model to prevent mortality of elderly subjects post hip fractures? A systematic review and meta-analysis based on current clinical practice. Int Orthop 43:1449-1454

3. United States Preventive Services Task Force. Grade definitions. https://www.uspreventiveservicestaskforce.org/Page/Name/grade -definitions. Accessed 26 Feb 2020

4. Bettelli G (2018) Preoperative evaluation of the elderly surgical patient and anesthesia challenges in the XXI century. Aging Clin Exp Res 30:229-235

5. Rubenstein LZ (2004) Joseph T. Freeman award lecture: comprehensive geriatric assessment: from miracle to reality. J Gerontol Ser A Biol Sci Med Sci 59:473-477

6. Feng MA, McMillan DT, Crowell K et al (2015) Geriatric assessment in surgical oncology: a systematic review. J Surg Res 193:265-272

7. Partridge JS, Harari D, Martin FC et al (2014) The impact of pre-operative comprehensive geriatric assessment on postoperative outcomes in older patients undergoing scheduled surgery: a systematic review. Anaesthesia 69(Suppl 1):8-16

8. Ellis G, Gardner M, Tsiachristas A et al (2017) Comprehensive geriatric assessment for older adults admitted to hospital. Cochrane Database Syst Rev 9:Cd006211

9. Pilotto A, Cella A, Pilotto A et al (2017) Three decades of comprehensive geriatric assessment: evidence coming from different healthcare settings and specific clinical conditions. J Am Med Dir Assoc 18:192.e1-e11

10. Fried LP, Ferrucci L, Darer J et al (2004) Untangling the concepts of disability, frailty, and comorbidity: implications for improved targeting and care. J Gerontol Ser A Biol Sci Med Sci 59:255-263

11. Barbagallo M, Dominguez LJ, Cucinotta D (2018) The place of frailty and vulnerability in the surgical risk assessment: should we move from complexity to simplicity? Aging Clin Exp Res 30:237-239

12. Chan SP, Ip KY, Irwin MG (2019) Peri-operative optimisation of elderly and frail patients: a narrative review. Anaesthesia 74(Suppl 1):80-89 
13. Chow WB, Rosenthal RA, Merkow RP et al (2012) Optimal preoperative assessment of the geriatric surgical patient: a best practices guideline from the American College of Surgeons National Surgical Quality Improvement Program and the American Geriatrics Society. J Am Coll Surg 215:453-466

14. Robinson TN, Walston JD, Brummel NE et al (2015) Frailty for surgeons: review of a National Institute on Aging Conference on Frailty for Specialists. J Am Coll Surg 221:1083-1092

15. Rolfson DB, Majumdar SR, Tsuyuki RT et al (2006) Validity and reliability of the Edmonton Frail Scale. Age Ageing 35:526-529

16. Kumar C, Salzman B, Colburn JL (2018) Preoperative assessment in older adults: a comprehensive approach. Am Fam Phy 98:214-220

17. Batchelor TJP, Rasburn NJ, Abdelnour-Berchtold E et al (2019) Guidelines for enhanced recovery after lung surgery: recommendations of the Enhanced Recovery After Surgery (ERAS(R)) Society and the European Society of Thoracic Surgeons (ESTS). Eur J Cardiothorac Surg 55:91-115

18. Li C, Carli F, Lee L (2013) Impact of a trimodal prehabilitation program on functional recovery after colorectal cancer surgery: a pilot study. Surg Endosc 27:1072-1082

19. Levett DZH, Jack S, Swart M et al (2018) Perioperative cardiopulmonary exercise testing (CPET): consensus clinical guidelines on indications, organization, conduct, and physiological interpretation. Br J Anaesth 120:484-500

20. Tinetti ME, Baker DI, McAvay G et al (1994) A multifactorial intervention to reduce the risk of falling among elderly people living in the community. N Engl J Med 331:821-827

21. Jones TS, Dunn CL, Wu DS et al (2013) Relationship between asking an older adult about falls and surgical outcomes. JAMA Surg 148:1132-1138

22. Summary of the Updated American Geriatrics Society/British Geriatrics Society clinical practice guideline for prevention of falls in older persons (2011) J Am Geriatr Soc 59:148-157

23. Whitson HE, Cronin-Golomb A, Cruickshanks KJ et al (2018) American Geriatrics Society and National Institute on Aging Bench-to-Bedside Conference: sensory impairment and cognitive decline in older adults. J Am Geriatr Soc 66:2052-2058

24. Gajdos C, Kile D, Hawn MT et al (2015) The significance of preoperative impaired sensorium on surgical outcomes in nonemergent general surgical operations. JAMA Surg 150:30-36

25. Inouye SK, Bogardus ST Jr, Charpentier PA et al (1999) A multicomponent intervention to prevent delirium in hospitalized older patients. N Eng J Med 340:669-676

26. Bacigalupo I, Mayer F, Lacorte E et al (2018) A systematic review and meta-analysis on the prevalence of dementia in Europe: estimates from the highest-quality studies adopting the DSM IV diagnostic criteria. J Alzheimer's Dis 66:1471-1481

27. Limongi F, Siviero P, Noale M et al (2017) Prevalence and conversion to dementia of mild cognitive impairment in an elderly Italian population. Aging Clin Exp Res 29:361-370

28. Gauthier S, Reisberg B, Zaudig M et al (2006) Mild cognitive impairment. Lancet 367:1262-1270

29. Petersen RC (2011) Clinical practice. Mild cognitive impairment. N Engl J Med 364:2227-2234

30. Plassman BL, Langa KM, Fisher GG et al (2008) Prevalence of cognitive impairment without dementia in the United States. Ann Intern Med 148:427-434

31. Crosby G, Culley DJ, Hyman BT (2011) Preoperative cognitive assessment of the elderly surgical patient: a call for action. Anesthesiology 114:1265-1268

32. Oresanya LB, Lyons WL, Finlayson E (2014) Preoperative assessment of the older patient: a narrative review. JAMA 311:2110-2120
33. Robinson TN, Wu DS, Pointer LF et al (2012) Preoperative cognitive dysfunction is related to adverse postoperative outcomes in the elderly. J Am Coll Surg 215:12-18

34. Bettelli G (2011) Preoperative evaluation in geriatric surgery: comorbidity, functional status and pharmacological history. Minerva Anestesiol 77:637-646

35. Wei J, Zeng L, Li S et al (2019) Relationship between comorbidities and treatment decision-making in elderly hip fracture patients. Aging Clin Exp Res 31:1735-1741

36. Griffiths R, Beech F, Brown A et al (2014) Peri-operative care of the elderly 2014: Association of Anaesthetists of Great Britain and Ireland. Anaesthesia 69(Suppl 1):81-98

37. Fleisher LA, Fleischmann KE, Auerbach AD et al (2014) 2014 ACC/AHA guideline on perioperative cardiovascular evaluation and management of patients undergoing noncardiac surgery: executive summary: a report of the American College of Cardiology/American Heart Association Task Force on Practice Guidelines. Circulation 130:2215-2245

38. Freeman WK, Gibbons RJ (2009) Perioperative cardiovascular assessment of patients undergoing noncardiac surgery. Mayo Clin Proc 84:79-90

39. Lee TH, Marcantonio ER, Mangione CM et al (1999) Derivation and prospective validation of a simple index for prediction of cardiac risk of major noncardiac surgery. Circulation 100:1043-1049

40. Alrezk R, Jackson N, Al Rezk M et al (2017) Derivation and validation of a geriatric-sensitive perioperative cardiac risk index. $\mathrm{J}$ Am Heart Assoc 6:e006648

41. Bilimoria KY, Liu Y, Paruch JL et al (2013) Development and evaluation of the universal ACS NSQIP surgical risk calculator: a decision aid and informed consent tool for patients and surgeons. J Am Coll Surg 217:833-842

42. Markovic DZ, Jevtovic-Stoimenov T, Cosic V et al (2018) Addition of biomarker panel improves prediction performance of American College of Surgeons National Surgical Quality Improvement Program (ACS NSQIP) calculator for cardiac risk assessment of elderly patients preparing for major non-cardiac surgery: a pilot study. Aging Clin Exp Res 30:419-431

43. Kozek-Langenecker S, Fenger-Eriksen C, Thienpont E et al (2018) European guidelines on perioperative venous thromboembolism prophylaxis: surgery in the elderly. Eur J Anaesth 35:116-122

44. Epidemiology, practice of ventilation and outcome for patients at increased risk of postoperative pulmonary complications: LAS VEGAS - an observational study in 29 countries (2017) Eur J Anaesth 34:492-507

45. Perilli V, Aceto P, Ancona P et al (2018) Role of surgical setting and patients-related factors in predicting the occurrence of postoperative pulmonary complications after abdominal surgery. Eur Rev Med Pharmacol Sci 22:547-550

46. Smetana GW (2003) Preoperative pulmonary assessment of the older adult. Clin Geriatr Med 19:35-55

47. Canet J, Gallart L, Gomar C et al (2010) Prediction of postoperative pulmonary complications in a population-based surgical cohort. Anesthesiology 113:1338-1350

48. Mazo V, Sabate S, Canet J et al (2014) Prospective external validation of a predictive score for postoperative pulmonary complications. Anesthesiology 121:219-231

49. Katsura M, Kuriyama A, Takeshima T et al (2015) Preoperative inspiratory muscle training for postoperative pulmonary complications in adults undergoing cardiac and major abdominal surgery. Cochrane Database Syst Rev 2015:Cd010356

50. Boden I, Skinner EH, Browning L et al (2018) Preoperative physiotherapy for the prevention of respiratory complications after upper abdominal surgery: pragmatic, double blinded, multicentre randomised controlled trial. BMJ (Clin Res) 360:j5916 
51. Musallam KM, Tamim HM, Richards T et al (2011) Preoperative anaemia and postoperative outcomes in non-cardiac surgery: a retrospective cohort study. Lancet 378:1396-1407

52. Nissenson AR, Goodnough LT, Dubois RW (2003) Anemia: not just an innocent bystander? Arch Int Med 163:1400-1404

53. Munoz M, Acheson AG, Auerbach $M$ et al (2017) International consensus statement on the peri-operative management of anaemia and iron deficiency. Anaesthesia 72:233-247

54. Goodnough LT, Schrier SL (2014) Evaluation and management of anemia in the elderly. Am J Hematol 89:88-96

55. Mueller MM, Van Remoortel H, Meybohm P et al (2019) Patient Blood management: recommendations from the 2018 Frankfurt Consensus Conference. JAMA 321:983-997

56. Spahn DR, Theusinger OM, Hofmann A (2012) Patient blood management is a win-win: a wake-up call. Br J Anaesth 108:889-892

57. Franchini M, Marano G, Veropalumbo E et al (2019) Patient blood management: a revolutionary approach to transfusion medicine. Blood Transfus 17:191-195

58. Cinnella G, Pavesi M, De Gasperi A et al (2019) Clinical standards for patient blood management and perioperative hemostasis and coagulation management. Position Paper of the Italian Society of Anesthesia, Analgesia, Resuscitation and Intensive Care (SIAARTI). Minerva Anestesiol 85:635-664

59. Franchini M, Marano G, Mengoli C et al (2017) Red blood cell transfusion policy: a critical literature review. Blood Transfus 15:307-317

60. Wirtz D, Kohlhof H (2019) The geriatric patient: special aspects of peri-operative management. EFORT Open Rev 4:240-247

61. Kim S, Brooks AK, Groban L (2015) Preoperative assessment of the older surgical patient: honing in on geriatric syndromes. Clin Interv Aging 10:13-27

62. van Stijn MF, Korkic-Halilovic I, Bakker MS et al (2013) Preoperative nutrition status and postoperative outcome in elderly general surgery patients: a systematic review. J Parenter Enteral Nutr 37:37-43

63. Corish CA (2001) Pre-operative nutritional assessment in the elderly. J Nutr Health Aging 5:49-59

64. Kaiser MJ, Bauer JM, Ramsch C et al (2010) Frequency of malnutrition in older adults: a multinational perspective using the mini nutritional assessment. J Am Geriatr Soc 58:1734-1738

65. Weimann A, Braga M, Carli F et al (2017) ESPEN guideline: clinical nutrition in surgery. Clin Nutr 36:623-650

66. Arozullah AM, Daley J, Henderson WG, Khuri SF (2000) Multifactorial risk index for predicting postoperative respiratory failure in men after major noncardiac surgery. The National Veterans Administration Surgical Quality Improvement Program. Ann Surg 232:242-253

67. Khuri SF, Daley J, Henderson W et al (1997) Risk adjustment of the postoperative mortality rate for the comparative assessment of the quality of surgical care: results of the National Veterans Affairs Surgical Risk Study. J Am Coll Surg 185:315-327

68. Tommasino $\mathrm{T}$ (2017) Diagnosis and treatment of nutritional deficits. In: Bettelli G (ed) Perioperative care of the elderly. Clinical and organizational aspects. Cambridge University Press, Cambridge, pp 90-96

69. Finlayson E, Maselli J, Steinman MA et al (2011) Inappropriate medication use in older adults undergoing surgery: a national study. J Am Geriatr Soc 59:2139-2144

70. Aldecoa C, Bettelli G, Bilotta F et al (2017) European Society of Anaesthesiology evidence-based and consensus-based guideline on postoperative delirium. Eur J Anaesth 34:192-214

71. Gorup E, Rifel J, Petek Ster M (2018) Anticholinergic burden and most common anticholinergic-acting medicines in older general practice patients. Zdr Varst 57:140-147
72. Mohanty S, Rosenthal RA, Russell MM et al (2016) Optimal perioperative management of the geriatric patient: a best practices guideline from the American College of Surgeons NSQIP and the American Geriatrics Society. J Am Coll Surg 222:930-947

73. Zhang X, Zhou S, Pan K et al (2017) Potentially inappropriate medications in hospitalized older patients: a cross-sectional study using the Beers 2015 criteria versus the 2012 criteria. Clin Interv Aging 12:1697-1703

74. O'Mahony D, O'Sullivan D, Byrne S et al (2015) STOPP/ START criteria for potentially inappropriate prescribing in older people: version 2. Age Ageing 44:213-218 (Published correction appears in Age Ageing 2018;47:489)

75. Association AP, Task Force DSM (2013) Diagnostic and statistical manual of mental disorders: DSM-5 ${ }^{\mathrm{TM}}$, 5th edn. American Psychiatric Publishing, Arlington

76. World Health Organization (2016) International statistical classification of diseases and related health problems 10th revision. https://icd.who.int/browse10/2016/en. Accessed 26 Feb 2020

77. Scottish Intercollegiate Guidelines Network (SIGN) (2019) Risk reduction and management of delirium: a national clinical guideline. https://www.sign.ac.uk/assets/sign157.pdf. Accessed 26 Feb 2020

78. National Institute for Health and Care Excellence (NICE) (2019) Delirium: prevention, diagnosis and management. Clinical guideline [CG103]. https://www.nice.org.uk/guida nce/cg 103. Accessed 26 Feb 2020

79. LaMantia MA, Messina FC, Hobgood CD et al (2014) Screening for delirium in the emergency department: a systematic review. Ann Emerg Med 63:551-560

80. Neto AS, Nassar AP Jr, Cardoso SO et al (2012) Delirium screening in critically ill patients: a systematic review and meta-analysis. Crit Care Med 40:1946-1951

81. Bettelli G, Neuner B (2017) Postoperative delirium: a preventable complication in the elderly surgical patient. Monaldi Arch Chest Dis 87:842

82. Neuner B, Hadzidiakos D, Bettelli G (2018) Pre- and postoperative management of risk factors for postoperative delirium: who is in charge and what is its essence? Aging Clin Exp Res $30: 245-248$

83. O'Sullivan D, Brady N, Manning E et al (2018) Validation of the 6-Item Cognitive Impairment Test and the 4AT test for combined delirium and dementia screening in older Emergency Department attendees. Age Ageing 47:61-68

84. Hendry K, Quinn TJ, Evans J et al (2016) Evaluation of delirium screening tools in geriatric medical inpatients: a diagnostic test accuracy study. Age Ageing 45:832-837

85. Shafer SL (2000) The pharmacology of anesthetic drugs in elderly patients. Anesthesiol Clin N Am 18:1-29

86. Defrin R, Amanzio M, de Tommaso M et al (2015) Experimental pain processing in individuals with cognitive impairment: current state of the science. Pain 156:1396-1408

87. Bettelli G (2017) Safety in the operating room: special needs of geriatric patients. In: Bettelli G (ed) Perioperative care of the elderly. Clinical and organizational aspects. Cambridge University Press, Cambridge, pp 120-124

88. Horgas AL, Nichols AL, Schapson CA et al (2007) Assessing pain in persons with dementia: relationships among the non-communicative patient's pain assessment instrument, selfreport, and behavioral observations. Pain Manag Nurs 8:77-85

89. Warden V, Hurley AC, Volicer L (2003) Development and psychometric evaluation of the Pain Assessment in Advanced Dementia (PAINAD) scale. J Am Med Dir Assoc 4:9-15

90. Kothari A, Phillips S, Bretl T et al (2011) Components of geriatric assessments predict thoracic surgery outcomes. J Surg Res 166:5-13 
91. Duivenvoorden T, Vissers MM, Verhaar JA et al (2013) Anxiety and depressive symptoms before and after total hip and knee arthroplasty: a prospective multicentre study. Osteoarthr Cartil 21:1834-1840

92. Leung JM, Sands LP, Mullen EA et al (2005) Are preoperative depressive symptoms associated with postoperative delirium in geriatric surgical patients? J Gerontol Ser A Biol Sci Med Sci 60:1563-1568

93. Burke WJ, Roccaforte WH, Wengel SP (1991) The short form of the Geriatric Depression Scale: a comparison with the 30-item form. J Geriatr Psychiatry Neurol 4:173-178

94. Kenig J, Olszewska U, Zychiewicz B et al (2015) Cumulative deficit model of geriatric assessment to predict the postoperative outcomes of older patients with solid abdominal cancer. J Geriatr Oncol 6:370-379

95. Guay J, Choi P, Suresh S et al (2014) Neuraxial blockade for the prevention of postoperative mortality and major morbidity: an overview of Cochrane systematic reviews. Cochrane Database Syst Rev 2014:Cd010108

96. Kruijt Spanjer MR, Bakker NA, Absalom AR (2011) Pharmacology in the elderly and newer anaesthesia drugs. Best Pract Res Clin Anaesthesiol 25:355-365

97. Steinmetz J, Rasmussen LS (2010) The elderly and general anesthesia. Minerva Anestesiol 76:745-752

98. Tommasino C, Corcione A (2018) Anesthesia for the elderly patient. In: Crucitti A (ed) Surgical management of elderly patients. Springer International Publishing, New York, pp 9-29

99. Phillips AT, Deiner S, Mo Lin H et al (2015) Propofol use in the elderly population: prevalence of overdose and association with 30-day mortality. Clin Ther 37:2676-2685

100. Schnider TW, Minto CF, Shafer SL et al (1999) The influence of age on propofol pharmacodynamics. Anesthesiology 90:1502-1516

101. National Institute of Health and Care Excellence (NICE) (2012) Depth of anaesthesia monitors-Bispectral Index (BIS), E-Entropy and Narcotrend-Compact M. Diagnostics guidance [DG6]. https://www.nice.org.uk/guidance/dg6. Accessed 26 Feb 2020

102. Brioni JD, Varughese S, Ahmed R et al (2017) A clinical review of inhalation anesthesia with sevoflurane: from early research to emerging topics. J Anesth 31:764-778

103. Nickalls RW, Mapleson WW (2003) Age-related iso-MAC charts for isoflurane, sevoflurane and desflurane in man. $\mathrm{Br} \mathrm{J}$ Anaesth 91:170-174

104. Chan MT, Cheng BC, Lee TM et al (2013) BIS-guided anesthesia decreases postoperative delirium and cognitive decline. J Neurosurg Anesthesiol 25:33-42

105. Radtke FM, Franck M, Lendner J et al (2013) Monitoring depth of anaesthesia in a randomized trial decreases the rate of postoperative delirium but not postoperative cognitive dysfunction. Br J Anaesth 110(Suppl 1):i98-i105

106. Schneider G, Sebel PS (1997) Monitoring depth of anaesthesia. Eur J Anaesth 15(Supplement):21-28

107. Hajat Z, Ahmad N, Andrzejowski J (2017) The role and limitations of EEG-based depth of anaesthesia monitoring in theatres and intensive care. Anaesthesia 72(Suppl 1):38-47

108. Zorrilla-Vaca A, Healy RJ, Wu CL et al (2017) Relation between bispectral index measurements of anesthetic depth and postoperative mortality: a meta-analysis of observational studies. Can J Anaesth 64:597-607

109. Aceto P, Lai C, Perilli V et al (2013) Stress-related biomarkers of dream recall and implicit memory under anaesthesia. Anaesthesia 68:1141-1147

110. Aceto P, Perilli V, Lai C et al (2013) Update on post-traumatic stress syndrome after anesthesia. Eur Rev Med Pharmacol Sci $17: 1730-1737$
111. Sieber FE, Neufeld KJ, Gottschalk A et al (2018) Effect of depth of sedation in older patients undergoing hip fracture repair on postoperative delirium: the STRIDE randomized clinical trial. JAMA Surg 153:987-995

112. Cope TM, Hunter JM (2003) Selecting neuromuscular-blocking drugs for elderly patients. Drugs Aging 20:125-140

113. Lee LA, Athanassoglou V, Pandit JJ (2016) Neuromuscular blockade in the elderly patient. J Pain Res 9:437-444

114. Biro P, Paul G, Dahan A et al (2019) Proposal for a revised classification of the depth of neuromuscular block and suggestions for further development in neuromuscular monitoring. Anesth Analg 128:1361-1363

115. Cedborg AI, Sundman E, Boden K et al (2014) Pharyngeal function and breathing pattern during partial neuromuscular block in the elderly: effects on airway protection. Anesthesiology 120:312-325

116. Young WL, Matteo RS, Ornstein E (1988) Duration of action of neostigmine and pyridostigmine in the elderly. Anesth Analg 67:775-778

117. Stone JG, Matteo RS, Ornstein E et al (1995) Aging alters the pharmacokinetics of pyridostigmine. Anesth Analg 81:773-776

118. Matteo RS, Young WL, Ornstein E et al (1990) Pharmacokinetics and pharmacodynamics of edrophonium in elderly surgical patients. Anesth Analg 71:334-339

119. McDonagh DL, Benedict PE, Kovac AL et al (2011) Efficacy, safety, and pharmacokinetics of sugammadex for the reversal of rocuronium-induced neuromuscular blockade in elderly patients. Anesthesiology 114:318-329

120. Carron M, Zarantonello F, Tellaroli P et al (2016) Efficacy and safety of sugammadex compared to neostigmine for reversal of neuromuscular blockade: a meta-analysis of randomized controlled trials. J Clin Anesth 35:1-12

121. Muramatsu T, Isono S, Ishikawa T et al (2018) Differences of recovery from rocuronium-induced deep paralysis in response to small doses of sugammadex between elderly and nonelderly patients. Anesthesiology 129:901-911

122. $\mathrm{Xu} \mathrm{H}, \mathrm{Xu} \mathrm{G}$, Ren $\mathrm{C}$ et al (2019) Effect of forced-air warming system in prevention of postoperative hypothermia in elderly patients: a prospective controlled trial. Medicine 98:e15895

123. Ma H, Lai B, Dong $\mathrm{S}$ et al (2017) Warming infusion improves perioperative outcomes of elderly patients who underwent bilateral hip replacement. Medicine 96:e6490

124. Miller TE, Myles PS (2019) Perioperative fluid therapy for major surgery. Anesthesiology 130:825-832

125. Feldheiser A, Aziz O, Baldini G et al (2016) Enhanced Recovery After Surgery (ERAS) for gastrointestinal surgery, part 2: consensus statement for anaesthesia practice. Acta Anaesthesiol Scand 60:289-334

126. Gupta R, Gan TJ (2016) Peri-operative fluid management to enhance recovery. Anaesthesia 71(Suppl 1):40-45

127. Myles PS, Bellomo R, Corcoran T et al (2018) Restrictive versus liberal fluid therapy for major abdominal surgery. N Engl J Med 378:2263-2274

128. Giglio M, Manca F, Dalfino L et al (2016) Perioperative hemodynamic goal-directed therapy and mortality: a systematic review and meta-analysis with meta-regression. Minerva Anestesiol 82:1199-1213

129. Brienza N, Biancofiore G, Cavaliere F et al (2019) Clinical guidelines for perioperative hemodynamic management of non cardiac surgical adult patients. Minerva Anestesiol 85:1315-1333

130. Greinacher A, Fendrich K, Brzenska R et al (2011) Implications of demographics on future blood supply: a population-based cross-sectional study. Transfusion 51:702-709

131. Vaglio S, Gentili S, Marano G et al (2017) The Italian Regulatory Guidelines for the implementation of Patient Blood Management. Blood Transfus 15:325-328 
132. Zerah L, Dourthe L, Cohen-Bittan J et al (2018) Retrospective evaluation of a restrictive transfusion strategy in older adults with hip fracture. J Am Geriatr Soc 66:1151-1157

133. Meybohm P, Lindau S, Treskatsch S et al (2019) Liberal transfusion strategy to prevent mortality and anaemia-associated, ischaemic events in elderly non-cardiac surgical patients - the study design of the LIBERAL-Trial. Trials 20:101

134. Wu WC, Smith TS, Henderson WG et al (2010) Operative blood loss, blood transfusion, and 30-day mortality in older patients after major noncardiac surgery. Ann Surg 252:11-17

135. Bates AT, Divino C (2015) Laparoscopic surgery in the elderly: a review of the literature. Aging Dis 6:149-155

136. Zhou S, Wang X, Zhao C et al (2019) Laparoscopic vs open colorectal cancer surgery in elderly patients: short- and long-term outcomes and predictors for overall and disease-free survival. BMC Surg 19:137

137. Hoshino N, Fukui Y, Hida K et al (2019) Short-term outcomes of laparoscopic surgery for colorectal cancer in the elderly versus non-elderly: a systematic review and meta-analysis. Int J Colorect Dis 34:377-386

138. Ceccarelli G, Andolfi E, Biancafarina A et al (2017) Robotassisted surgery in elderly and very elderly population: our experience in oncologic and general surgery with literature review. Aging Clin Exp Res 29:55-63

139. Ljungqvist $\mathrm{O}$, Scott M, Fearon KC (2017) Enhanced recovery after surgery: a review. JAMA Surg 152:292-298

140. Parks L, Routt M, De Villiers A (2018) Enhanced recovery after surgery. J Adv Pract Oncol 9:511-519

141. Ljungqvist O, Hubner M (2018) Enhanced recovery after surgery-ERAS-principles, practice and feasibility in the elderly. Aging Clin Exp Res 30:249-252

142. Tejedor P, Pastor C, Gonzalez-Ayora S et al (2018) Short-term outcomes and benefits of ERAS program in elderly patients undergoing colorectal surgery: a case-matched study compared to conventional care. Int J Colorect Dis 33:1251-1258

143. Inouye SK, van Dyck CH, Alessi CA et al (1990) Clarifying confusion: the confusion assessment method. A new method for detection of delirium. Ann Intern Med 113:941-948

144. Leentjens AF, Molag ML, Van Munster BC et al (2014) Changing perspectives on delirium care: the new Dutch guideline on delirium. J Psychosom Res 77:240-241

145. Bellelli G, Morandi A, Davis DH et al (2014) Validation of the 4AT, a new instrument for rapid delirium screening: a study in 234 hospitalised older people. Age Ageing 43:496-502

146. Bellelli G, Morandi A, Trabucchi M et al (2018) Italian intersociety consensus on prevention, diagnosis, and treatment of delirium in hospitalized older persons. Intern Emerg Med 13:113-121

147. Flaherty JH, Tariq SH, Raghavan S et al (2003) A model for managing delirious older inpatients. J Am Geriatr Soc 51:1031-1035

148. Aceto P, Lai C, De Crescenzo F et al (2019) Cognitive decline after carotid endarterectomy: systematic review and meta-analysis. Eur J Anaesthiol. https://doi.org/10.1097/EJA.0000000000 001130

149. Belrose JC, Noppens RR (2019) Anesthesiology and cognitive impairment: a narrative review of current clinical literature. BMC Anesthesiol 19:241

150. Garcia PS, Duggan EW, McCullough IL et al (2015) Postanesthesia care for the elderly patient. Clin Ther 37:2651-2665

151. American Geriatrics Society (2015) Updated beers criteria for potentially inappropriate medication use in older adults. J Am Geriatr Soc 63:2227-2246

152. Fong HK, Sands LP, Leung JM (2006) The role of postoperative analgesia in delirium and cognitive decline in elderly patients: a systematic review. Anesth Analg 102:1255-1266
153. Sammons G, Ritchey W (2015) Use of transversus abdominis plane (TAP) blocks for pain management in elderly surgical patients. AORN J 102:493-497

154. Miskovic A, Lumb AB (2017) Postoperative pulmonary complications. Br J Anaesth 118:317-334

155. Smetana GW, Lawrence VA, Cornell JE (2006) Preoperative pulmonary risk stratification for noncardiothoracic surgery: systematic review for the American College of Physicians. Ann Intern Med 144:581-595

156. Schumann R, Harvey B, Zahedi F et al (2019) Minute ventilation assessment in the PACU is useful to predict postoperative respiratory depression following discharge to the floor: a prospective cohort study. J Clin Anesth 52:93-98

157. Eltorai AEM, Baird GL, Eltorai AS et al (2018) Perspectives on incentive spirometry utility and patient protocols. Respir Care 63:519-531

158. Eltorai AEM, Baird GL, Eltorai AS et al (2018) Incentive spirometry adherence: a national survey of provider perspectives. Respir Care 63:532-537

159. Sieber FE, Barnett SR (2011) Preventing postoperative complications in the elderly. Anesthesiol Clin 29:83-97

160. KDIGO (2018) Clinical practice guideline for the prevention, diagnosis, evaluation, and treatment of hepatitis $\mathrm{C}$ in chronic kidney disease. Kidney Int Suppl 8:91-165

161. Conway LJ, Larson EL (2012) Guidelines to prevent catheterassociated urinary tract infection: 1980 to 2010. Heart Lung 41:271-283

162. Patel DN, Felder SI, Luu M et al (2018) Early urinary catheter removal following pelvic colorectal surgery: a prospective, randomized, noninferiority trial. Dis Colon Rectum 61:1180-1186

163. Potter J, Klipstein K, Reilly JJ et al (1995) The nutritional status and clinical course of acute admissions to a geriatric unit. Age Ageing 24:131-136

164. Herbert G, Perry R, Andersen HK et al (2018) Early enteral nutrition within 24 hours of lower gastrointestinal surgery versus later commencement for length of hospital stay and postoperative complications. Cochrane Database Syst Rev 10:Cd004080

165. Lewis SJ, Andersen HK, Thomas S (2009) Early enteral nutrition within $24 \mathrm{~h}$ of intestinal surgery versus later commencement of feeding: a systematic review and meta-analysis. J Gastrointest Surg 13:569-575

166. Volkert D, Beck AM, Cederholm T et al (2019) ESPEN guideline on clinical nutrition and hydration in geriatrics. Clin Nutr 38:10-47

167. Lim SC, Koh IAJH (2017) Nutrition and the elderly surgical patients. MOJ Surg 4:114-120

168. Chiari P, Forni C, Guberti M et al (2017) Predictive factors for pressure ulcers in an older adult population hospitalized for hip fractures: a prognostic cohort study. PLoS ONE 12:e0169909

169. Liu Z, Dumville JC, Norman G et al (2018) Intraoperative interventions for preventing surgical site infection: an overview of cochrane reviews. Cochrane Database Syst Rev 2:Cd012653

170. Cataldo MA, Granata G, Petrosillo N (2017) Antibacterial prophylaxis for surgical site infection in the elderly: practical application. Drugs Aging 34:489-498

171. Yates AJ Jr (2018) Postoperative prophylactic antibiotics in total joint arthroplasty. Arthroplasty Today 4:130-131

172. Lee P, Min L, Mody L (2014) Perioperative glucose control and infection risk in older surgical patients. Curr Geriatr Rep 3:48-55

173. Ehrenfeld JM, Wanderer JP, Terekhov M et al (2017) A perioperative systems design to improve intraoperative glucose monitoring is associated with a reduction in surgical site infections in a diabetic patient population. Anesthesiology 126:431-440

174. Kwon S, Thompson R, Dellinger P et al (2013) Importance of perioperative glycemic control in general surgery: a report from 
the Surgical Care and Outcomes Assessment Program. Ann Surg 257:8-14

175. Evans CH, Lee J, Ruhlman MK (2015) Optimal glucose management in the perioperative period. Surg Clin N Am 95:337-354

176. Goncalves-Bradley DC, Lannin NA, Clemson LM et al (2016) Discharge planning from hospital. Cochrane Database Syst Rev 2016:Cd000313

177. Zurlo A, Zuliani G (2018) Management of care transition and hospital discharge. Aging Clin Exp Res 30:263-270

178. McNab D, Bowie P, Ross A et al (2018) Systematic review and meta-analysis of the effectiveness of pharmacist-led medication reconciliation in the community after hospital discharge. BMJ Qual Saf 27:308-320

179. Mixon AS, Neal E, Bell S et al (2015) Care transitions: a leverage point for safe and effective medication use in older adults-a mini-review. Gerontology 61:32-40

180. Krumholz HM (2013) Post-hospital syndrome-an acquired, transient condition of generalized risk. N Engl J Med 368:100-102

181. Brownlee SA, Blackwell RH, Blanco BA et al (2017) Impact of post-hospital syndrome on outcomes following elective, ambulatory surgery. Ann Surg 266:274-279
182. Robinson TN, Wallace JI, Wu DS et al (2011) Accumulated frailty characteristics predict postoperative discharge institutionalization in the geriatric patient. J Am Coll Surg 213:37-42

183. Rid A, Wesley R, Pavlick M et al (2015) Patients' priorities for treatment decision making during periods of incapacity: quantitative survey. Palliat Support Care 13:1165-1183

184. De Blasio E, Raffaelo de Gaudio A, Petrini F et al (2019) Strategie perioperatorie: presa in carico dell'anziano con gravi comorbilità e fase avanzata di malattia con patologia chirurgica acuta: SIAARTI 2019 [Perioperative strategies: taking care of the elderly with severe comorbidities and advanced stage of disease with acute surgical pathology]. https://www.siaarti.it/SiteAssets/ Ricerca/Strategie-perioperatorie-presa-in-carico-dell-anzianocon-gravi-comorbilità-e-fase-avanzata-di-malattia-con-patologia-chir/Strategie\%2520perioperatorie\%2520-\%2520SIAARTISIC.pdf. Accessed 26 Feb 2020

Publisher's Note Springer Nature remains neutral with regard to jurisdictional claims in published maps and institutional affiliations. 